\title{
Investigaciones arqueológicas en el sitio Las Brusquillas 3 (Holoceno tardío, región Pampeana, Argentina)
}

Agustina Massigoge*, M. Natalia Rodríguez" , Daniel J. Rafuse*, R. Florencia Torino**, Cristian Favier Dubois" y Pamela G. Steffan*
Recibido:

17 de marzo de 2017

Aceptado:

15 de junio de 2017

\begin{abstract}
Resumen
En este artículo se presentan y discuten los resultados del estudio del sitio Las Brusquillas 3, ubicado en la llanura Interserrana de la región Pampeana. El conjunto arqueológico recuperado está integrado por restos faunísticos, artefactos líticos y fragmentos de pigmento mineral, resultantes de ocupaciones cazadoras-recolectoras ocurridas durante el Holoceno tardío ( $c a .2800$ años ${ }^{14} \mathrm{C}$ AP). Se presenta la caracterización de la secuencia estratigráfica y los resultados del análisis tecno-morfológico de los artefactos líticos y del estudio zooarqueológico y tafonómico de los restos faunísticos. Los principales objetivos son evaluar la historia tafonómica y los procesos de formación del conjunto faunístico, identificar los recursos animales explotados y caracterizar la tecnología lítica. Los materiales se encontraban en un depósito fluvio-lacustre, sobre el cual se desarrolló un paleosuelo palustre. En el sitio se llevaron a cabo múltiples actividades, incluyendo el procesamiento y consumo de recursos faunísticos y la manufactura, reactivación y uso de instrumentos líticos. El guanaco fue la presa principal mientras que animales de menor porte constituyeron recursos complementarios. La tecnología lítica se caracteriza por la talla unifacial y el uso preferencial de ortocuarcita dentro de una estrategia de aprovisionamiento de los individuos.
\end{abstract}

\section{Archaeological research at the Las Brusquillas 3 site (Late Holocene, Pampean region, Argentina)}

\section{Palabras clave}

Cazadores-recolectores Llanura Interserrana Holoceno tardío Procesos de formación del registro Subsistencia Tecnología lítica

\begin{abstract}
This article presents the results of the analysis from the Las Brusquillas 3 site, located in the Interserrana grasslands of the Pampean region. The archaeological assemblage contains faunal remains, lithic artifacts, and mineral pigments from hunter-gatherer

* Investigaciones Arqueológicas y Paleontológicas del Cuaternario Pampeano (INCUAPA), Facultad de Ciencias Sociales, Universidad Nacional del Centro de la Provincia de Buenos Aires (UNICEN) - CONICET. Av. Del Valle 5737 (CP B740oJWI) Olavarría, Buenos Aires, Argentina. E-mail: amassigo@soc.unicen.edu.ar; drafuse@soc.unicen.edu.ar; cfavier3@gmail.com; psteffan@soc.unicen.edu.ar

** Facultad de Ciencias Sociales, Universidad Nacional del Centro de la Provincia de Buenos Aires (UNICEN). Av. Del Valle 5737 (CP B740oJWI) Olavarría, Buenos Aires, Argentina. E-mail: manataliarodriguez@gmail.com; florenciatorino@gmail.com
\end{abstract}


Keywords

Hunter-gatherers Interserrana grassland Late Holocene Formation processes Subsistence Lithic technology occupations dating to the Late Holocene (ca. 2,800 ${ }^{14} \mathrm{C}$ years BP). Here, we present a characterization of the stratigraphic sequence, a techno-morphological analysis of the lithic artifacts, and the zooarchaeological and taphonomic data of the faunal remains. The main objectives of this study are to evaluate the taphonomic history and formation processes of the faunal assemblage, identify the animal resources exploited, and characterize the lithic technology. Most of the archaeological material was recovered from a fluvio-lacustrine deposit, where a marshy palaeosol had developed. The results indicate that multiple human activities occurred at the site, including the processing and consumption of faunal resources, and the manufacture, re-sharpening, and use of lithic implements. The main prey was the guanaco and smaller-sized animals were used as complementary resources. The lithic technology is characterized by unifacial flaking, a preferential use of quartzite, and an individual raw material provisioning strategy.

\section{Introducción}

La localidad arqueológica Las Brusquillas (partido de San Cayetano, provincia de Buenos Aires) se ubica sobre la margen derecha del arroyo Cristiano Chico, en la llanura Interserrana de la región Pampeana (Figura 1). Desde los inicios de las investigaciones en esta localidad, en el año 2005, hasta la fecha, se han detectado cuatro sitios en posición estratigráfica, con ocupaciones cazadoras-recolectoras fechadas en el Holoceno medio y tardío (Massigoge, 2007, 2011, 2012). Las Brusquillas 1 (LB1) se emplaza sobre una lomada loéssica, a unos $200 \mathrm{~m}$ del cauce actual del arroyo (Figura 2). La unidad arqueológica Niveles Inferiores, para la cual se obtuvo un fechado de ca. 3300 años ${ }^{14} \mathrm{C}$ AP, fue interpretada como el resultado de ocupaciones de carácter residencial durante las cuales se llevó a cabo el procesamiento y consumo de recursos animales (principalmente guanaco -Lama guanicoe-) y la manufactura, mantenimiento y utilización de instrumentos, mayormente de ortocuarcita del Grupo Sierras Bayas -en adelante OGSB- (Massigoge, 2012; Massigoge y Pal, 2011). Las Brusquillas 2 (LB2) se localiza en la barranca del arroyo, en depósitos de una antigua planicie aluvial (Figura 2). El contexto arqueológico, contenido en una unidad sedimentaria de origen fluvio-lacustre (UIII), fue interpretado como el resultado de ocupaciones humanas de baja intensidad, datadas en $c a$. 1800 años ${ }^{14} \mathrm{C}$ AP, durante las cuales se realizaron diversas actividades, incluyendo la caza, el procesamiento y el consumo de recursos animales, principalmente guanaco. Asimismo, se propuso que un alto porcentaje de restos (mayormente de venado de las pampas -Ozotoceros bezoarticus-) fue incorporado al depósito por causas naturales (Massigoge, 2011). Las Brusquillas 4 (LB4) corresponde a un conjunto de restos faunísticos y artefactos líticos detectado en un sondeo realizado entre los sitios LB2 y LB3 (Figura 2). Estos materiales se encuentran en la misma unidad sedimentaria que aquellos de LB2, aunque a mayor profundidad. Un hueso de guanaco con fractura antrópica fue fechado en $5350 \pm 950$ años ${ }^{14} \mathrm{C}$ AP $\left(\mathrm{AA}-87929 ; \delta^{13} \mathrm{C}=-20,9 \%\right.$ ), aunque esta edad radiocarbónica debe ser tomada con precaución debido a la magnitud de su error estándar. Observaciones preliminares de los materiales recuperados sugieren el empleo preferencial de la OGSB para la manufactura de artefactos y la explotación de una mayor diversidad de recursos faunísticos en comparación con los otros sitios de la localidad, aunque aquí también el guanaco parece ser la presa principal.

En este trabajo se da a conocer información surgida de las investigaciones efectuadas en el sitio Las Brusquillas 3 (LB3), en el cual se recuperó un conjunto arqueológico asignado al Holoceno tardío. En particular, se presentan los resultados del estudio de la secuencia estratigráfica, del análisis zooarqueológico y tafonómico de los restos faunísticos y del análisis tecno-morfológico de los artefactos líticos. Los objetivos principales son: 1) evaluar la historia tafonómica y los procesos de formación del conjunto faunístico, 2) identificar los recursos animales explotados y su aporte a la 


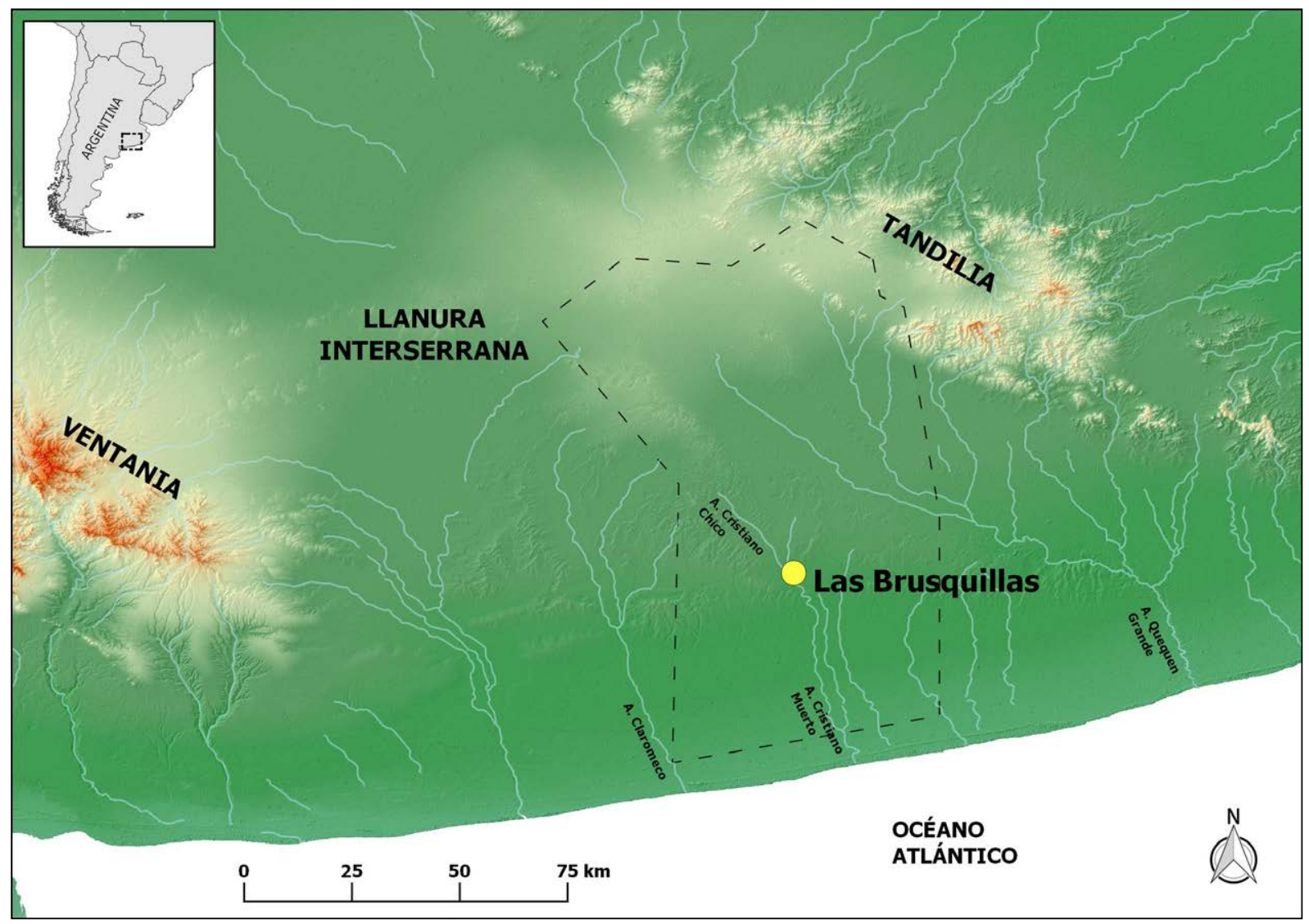

Figura 1. Mapa del sudeste pampeano, mostrando el área de estudio (línea punteada) y la ubicación de la localidad arqueológicas Las Brusquillas.

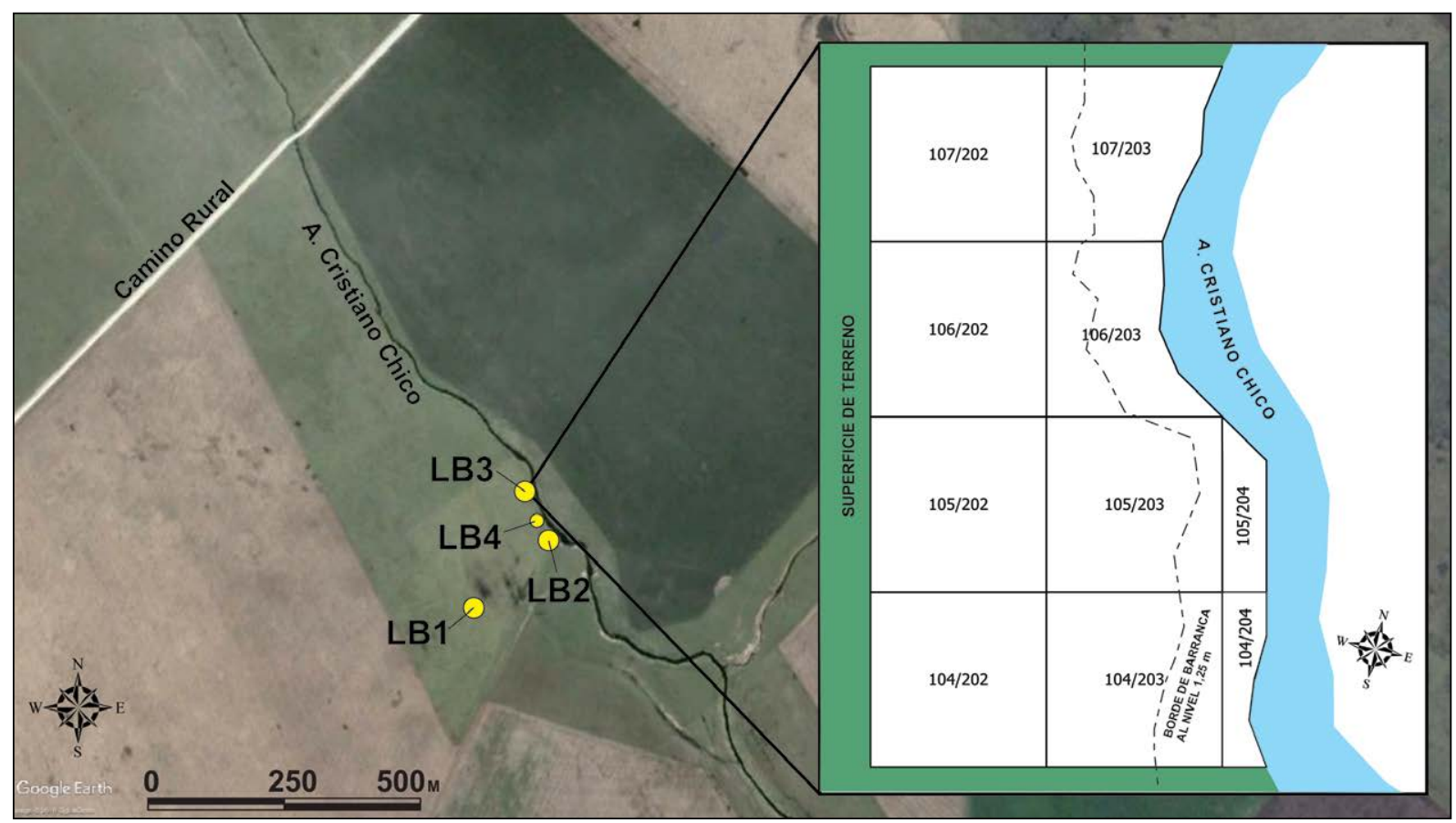

Figura 2. Imagen satelital (Google Earth 2016) mostrando la ubicación de los sitios de la localidad Las Brusquillas y la planta de excavación del sitio LB3. 
subsistencia y 3) caracterizar la tecnología lítica. Estas investigaciones forman parte de un proyecto arqueológico que se desarrolla en un sector de la llanura Interserrana comprendido entre las cuencas del arroyo Claromecó y del río Quequén Grande (ver Figura 1), el cual busca contribuir al conocimiento de los procesos evolutivos y la trayectoria histórica de las sociedades indígenas que habitaron el sudeste de la región pampeana en momentos previos a la conquista hispánica (Massigoge, 2007).

La región Pampeana es una extensa planicie con pastizales de gramíneas que se localiza en el centro-este de la Argentina. En su porción sud-oriental, esta planicie se encuentra interrumpida por los cordones serranos de Ventania y Tandilia, entre los cuales se extiende la llanura Interserrana. En las sierras, la oferta de rocas aptas para la talla es importante y variada, mientras que en la llanura este recurso es escaso y se encuentra restringido a afloramientos rocosos pequeños y aislados y al litoral atlántico, donde se presenta en forma de depósitos de rodados (Flegenheimer y Bayón, 2002).

Desde fines del Pleistoceno hasta momentos del contacto hispano-indígena, el sudeste pampeano fue habitado por sociedades cazadoras-recolectoras caracterizadas, en términos generales, por una alta movilidad residencial basada en parte en el uso complementario de ambientes y recursos de la llanura, las sierras y el litoral atlántico (Bayón, Flegenheimer y Pupio, 2006; Bonomo, 2005; Politis, 2008). En particular, para el Holoceno tardío ( $c a .3500$ años AP al contacto hispano-indígena), los investigadores han propuesto a nivel regional un aumento de la densidad poblacional, una reducción de la movilidad, un incremento de la territorialidad, un fortalecimiento de las relaciones de interacción con grupos extra-pampeanos, la incorporación de importantes innovaciones tecnológicas (e.g., cerámica y arco y flecha) y una diversificación e intensificación en la explotación de los recursos alimenticios (Bayón et al., 2006; Berón, 2007; González, 2005; Martínez y Gutiérrez, 2004; Mazzanti, 2006; Politis, 2012; Quintana y Mazzanti, 2001; entre otros). En general, los investigadores coinciden en que estos cambios no se debieron a una única causa, sino que se produjeron como consecuencia de la interacción de distintos factores de índole socio-cultural y económico-ambiental. Asimismo, estos cambios no se habrían producido todos al mismo tiempo ni de manera abrupta, por lo cual algunos autores han propuesto dividir este período en Holoceno tardío inicial (antes del 1000 AP) y final (post 1000 AP) (Quintana y Mazzanti, 2001; Stoessel y Martínez, 2014).

\section{Sitio Las Brusquillas 3: características generales, estratigrafía y cronología}

LB3 fue detectado en el 2006 a partir de la presencia de materiales arqueológicos expuestos en una pequeña barranca, a unos $60 \mathrm{~m}$ aguas arriba del sitio LB2. $\mathrm{Al}$ año siguiente, se llevó a cabo la excavación de un sondeo de $0,5 \times 0,5 \mathrm{~m}$ en el cual se recuperaron abundantes materiales faunísticos $(n=167)$ y líticos $(n=28)$. Posteriormente, en el año 2010, se abrieron diez unidades de excavación, seis de 1 por $1 \mathrm{~m}$ y cuatro de menores dimensiones delimitadas por la barranca (Figura 2). Debido a la inclinación que presentaba la barranca hacia el agua, el área excavada se amplió desde la superficie del terreno $\left(5,5 \mathrm{~m}^{2}\right)$ hacia la base de la excavación $\left(8 \mathrm{~m}^{2}\right)$. El nivel 0 se estableció a unos $40 \mathrm{~cm}$ por encima de la superficie del terreno, en el punto más elevado del área excavada. La excavación se realizó siguiendo niveles artificiales de $5 \mathrm{~cm}$ y todo el sedimento extraído se cernió bajo agua con una malla de $2,5 \mathrm{~mm}$ de abertura. Como resultado de estas actividades, se recuperaron 10.061 restos faunísticos, 732 artefactos líticos, 31 restos de carbón y ocho fragmentos minerales pigmentarios.

Al igual que en los sitios LB2 y LB4, en la secuencia sedimentaria de LB3 se reconocen cuatro unidades litoestratigráficas principales, separadas entre sí por discordancias, 
y dos unidades pedoestratigráficas (Figura 3). La unidad sedimentaria superior es un depósito arenoso (UI), de probable origen aluvial-coluvial, que se extiende hasta los 10 o $40 \mathrm{~cm}$ de profundidad desde la superficie (dependiendo de la pendiente del terreno); sobre esta unidad se ha desarrollado el suelo actual (perfil A-C). Por debajo, se observa un depósito también arenoso aunque de menor granulometría (UII), de origen fluvial, que se extiende hasta los 70-80 $\mathrm{cm}$ de profundidad. La unidad sedimentaria subyacente es un paquete sedimentario de limos con proporción variable de arena y arcilla, de origen fluvio-lacustre (UIII), que abarca desde los 70-80 cm hasta los 150-160 cm de profundidad. Sobre este depósito se desarrolló un paleosuelo palustre de carácter cumúlico de color negro y con alto contenido de materia orgánica (5,7\%) (horizonte $3 \mathrm{Ab} 1 \mathrm{cum})$. Cambios en la coloración y diferencias menores en la granulometría dentro de la UIII permiten diferenciar dos subunidades con contactos transicionales entre sí (UIIIa y UIIIb). Los valores de $\mathrm{pH}$ obtenidos para esta unidad se encuentran entre 8 y 8,38 indicando condiciones de alcalinidad. Los materiales arqueológicos se distribuyen en toda la potencia de la UIII, siendo más frecuentes en su porción media e inferior (Figura 3). Por último, en la base de la secuencia estratigráfica y en contacto ondulado y abrupto (discordancia) con la UIII, se observa un depósito sedimentario arenolimoso de color verdoso a castaño claro (Unidad IV), asignable al Miembro Guerrero de la Formación Luján (sensu Fidalgo, De Francesco y Colado, 1973).

Es importante mencionar que durante los trabajos de campo se registraron algunas cuevas rellenas de sedimento de animales de hábitos fosoriales, las cuales afectan principalmente a las dos unidades superiores. Debido a que no se recuperaron restos de individuos muertos en su interior, no es posible determinar el agente responsable de estos rasgos. No obstante, considerando las dimensiones de las galerías (unos 20 $\mathrm{cm}$ de diámetro), se cree que pudieron ser excavadas por armadillos, en particular Chaetophractus villosus y Dasypus hybridus, ya que estos animales habitan en la actualidad en las inmediaciones del sitio.

Con el fin de establecer la cronología de la ocupación humana se enviaron tres muestras óseas al NSF-Arizona AMS Laboratory para fechar por ${ }^{14} \mathrm{C}$. La ausencia de colágeno en dos de ellas no permitió su datación. La muestra restante, consistente en un fragmento de vértebra torácica de guanaco con huellas de corte (FCS.LB3.220; cuadrícula 104/202; nivel 175-180 cm), arrojó una edad de $2830 \pm 110$ años AP (AA-94556; $\delta^{13} \mathrm{C}=-24,2$ $\%$ ). Esta datación calibrada en años calendarios corresponde al lapso 1271-774 años cal a.C. $(\mathrm{p}=1)$ (Calibrado a 2 sigmas con el programa Calib 7.0.1; Stuiver y Reimer, 1993; usando SHCal13.14c; Hogg, et al., 2013).

\section{Materiales y métodos}

El estudio faunístico abarcó la totalidad de los restos recuperados en el sitio, incluyendo tanto los provenientes del sondeo como de la excavación ampliada $(\mathrm{n}=10.228)$. Por razones de espacio, en este trabajo solo se presenta una síntesis de los resultados del análisis de los especímenes recuperados en la UIII $(n=9.301)$ que es la que contiene al contexto arqueológico. El análisis zooarqueológico comprendió la cuantificación de la abundancia taxonómica y anatómica. La representación de los distintos taxones fue calculada a partir del número de especímenes identificados por taxón (NISP) (Payne, 1975). Todo espécimen que pudo ser asignado al menos a nivel de clase fue considerado identificado. Posteriormente, se estimó la abundancia relativa de cada taxón con respecto al NISP total (NISP\%). Las placas dérmicas y los fragmentos de valva y cáscara de huevo no fueron incluidos en el cálculo del NISP\%. Esto se debe a que estos elementos no están presentes en todas las especies, por lo cual se dificulta la comparación con el resto de los taxones. Cuando fue posible, los especímenes que no pudieron ser identificados a nivel taxonómico así como aquellos que solo pudieron ser identificados como Mammalia, 


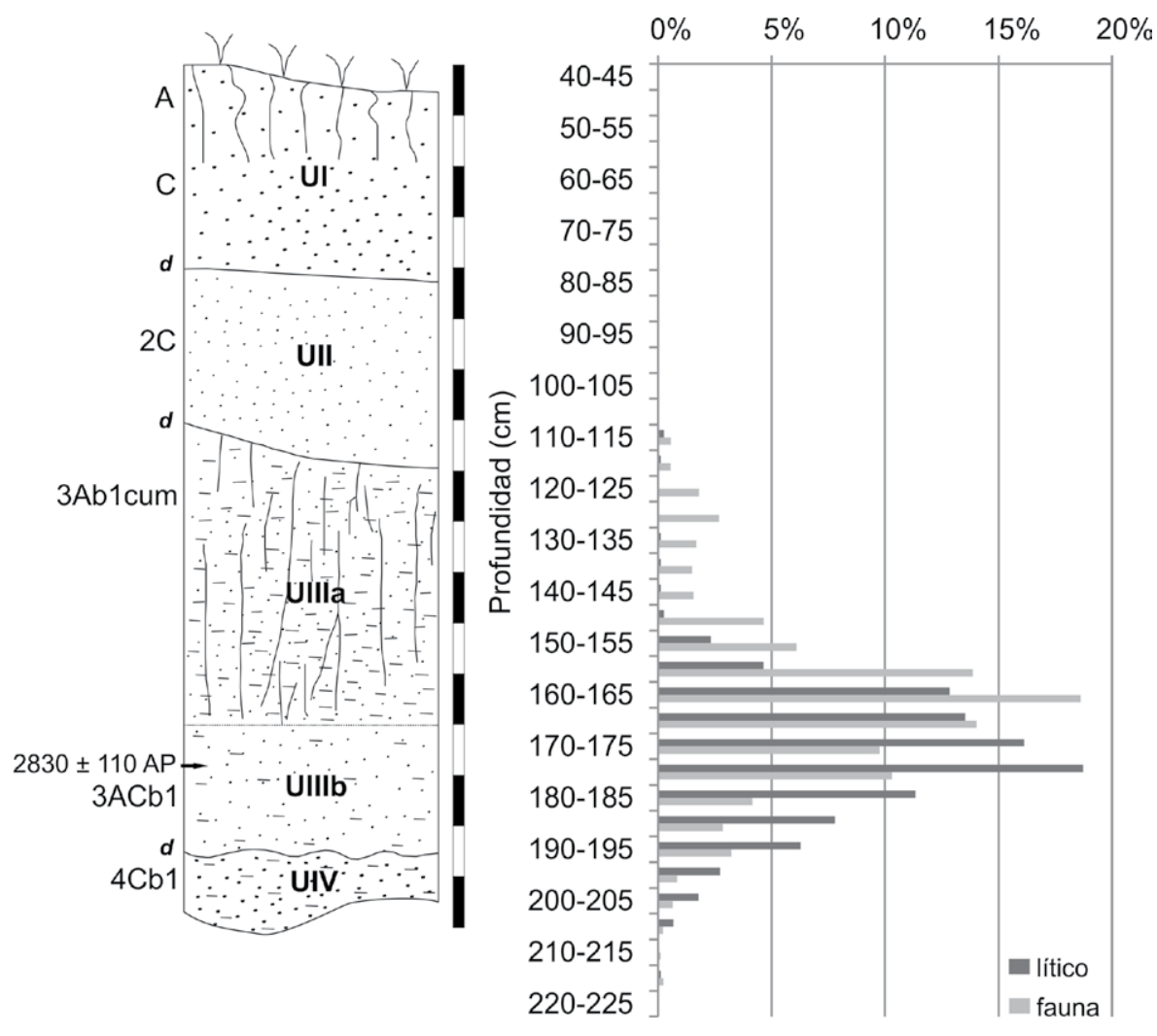

Figura 3. Esquema estratigráfico del sitio Las Brusquillas 3 (pared oeste de la cuadrícula 104/202) y distribución vertical de materiales líticos y faunísticos (profundidades expresadas en referencia al nivel o).

fueron asignados a las categorías de tamaño grande $(>15 \mathrm{~kg}$ de peso) y pequeño $(<15$ $\mathrm{kg}$ ) (Quintana y Mazzanti, 2010). En el caso del guanaco (Lama guanicoe) y del puma (Puma concolor), que son las especies más abundantes, se estimó el número mínimo de individuos (MNI) teniendo en cuenta los criterios de lateralidad y fusión ósea (Lyman, 1994; White, 1953). Por su parte, para el guanaco, que constituye la especie de mayor importancia en la subsistencia, se calculó la abundancia anatómica a través de las siguientes medidas: número mínimo de elementos (MNE), número mínimo de unidades anatómicas (MAU) y este último valor estandarizado (MAU\%) (Binford, 1984; Lyman, 1994). Por último, se evaluó si la representación anatómica de guanaco podría estar condicionada por la destrucción y/o el transporte hídrico diferencial, problemas que se encuentran mediados por la densidad ósea. Para evaluar la ocurrencia de procesos de destrucción diferencial, se consideró la diferencia entre las proporciones de la epífisis proximal (menos densa) y distal (más densa) para el húmero y la tibia (Binford, 1981). Por otro lado, la representación anatómica se comparó de modo cualitativo con el modelo de transporte hídrico disponible para guanaco, el cual considera distintas clases etarias (Kaufmann, Gutiérrez, Álvarez, González y Massigoge, 2011, Tabla 7).

Asimismo, se realizó el análisis tafonómico con el propósito de identificar los diferentes procesos -culturales y naturales-involucrados en la acumulación y modificación del conjunto faunístico. Se relevaron distintas variables siguiendo los criterios establecidos por distintos autores (Andrews, 1990; Behrensmeyer, 1978; Binford, 1981; Fisher, 1995; Gutiérrez y Kaufmann, 2007; Johnson, 1985; Lyman, 1994; Olsen y Shipman, 1988; entre otros). En cuanto a la abrasión geológica, se emplearon los estadios propuestos por Gutiérrez y Kaufmann (2007). Con respecto a las fracturas, se registró su presencia/ ausencia en el total de la muestra analizada mientras que en el caso particular de los huesos largos y la falange proximal se consignó también el estado del hueso al 
momento de la fragmentación (Johnson, 1985). Para los vertebrados grandes, el análisis tafonómico se efectuó sobre la totalidad de los restos óseos registrados en planta y una muestra de los de cernidor, compuesta por los especímenes determinados a nivel taxonómico y aquellos indeterminados mayores a $2 \mathrm{~cm}$. En el caso de los vertebrados pequeños, se analizaron todos los especímenes óseos y dentarios recuperados en planta y en cernidor, con la excepción de las placas dérmicas. Para estos últimos elementos, se relevó solo la presencia de alteración térmica y huellas de corte.

En cuanto al conjunto lítico, en total se recuperaron 760 artefactos, los cuales proceden en su mayoría de la UIII; por fuera de esta unidad, solo se recobraron dos desechos de talla en la UII. El conjunto fue dividido en subconjuntos según la materia prima, la cual se identificó a partir de la observación macroscópica. El estudio tecnomorfológico se realizó siguiendo la propuesta de Aschero $(1975,1983)$ para los instrumentos y núcleos y la de Bellelli, Guraieb y García (1985-1987), con algunas modificaciones introducidas por Martínez, Landini y Bonomo (1997-1998), para los desechos de talla.

\section{Conjunto faunístico}

\section{Representación taxonómica}

En la UIII del sitio LB3 se recuperó un total de 9.301 especímenes faunísticos (Tabla 1), incluyendo restos óseos y dentarios ( $\mathrm{n}=9.295$, de los cuales 1.266 corresponden a placas dérmicas), fragmentos de gastrópodos terrestres $(n=5)$ y fragmentos de cáscara de huevo $(\mathrm{n}=1)$. Debido al alto grado de fragmentación que presenta el conjunto, un $74,5 \%$ de los especímenes no pudo ser identificado a nivel taxonómico. Como se observa en la Tabla 1, gran parte de los restos identificados corresponde a vertebrados grandes. Dentro de este grupo, la especie más abundante es guanaco (NISP\% $=36,8$; $\mathrm{MNI}=6)$, seguida por puma -Puma concolor- $(\mathrm{NISP} \%=8,1 ; \mathrm{MNI}=1)$. En menores frecuencias se encuentran el venado de las pampas -Ozotoceros bezoarticus- (NISP\% $=0,5)$ y el ñandú -Rhea americana- (NISP\% $=0,3$ ). Un aspecto destacado es que gran parte de los restos de puma se encontraban agrupados en el sector sur del área excavada, distribuidos verticalmente entre 117 y 152,5 cm de profundidad desde el nivel 0 (porción superior de la UIII). Distintos indicadores, entre los que se puede mencionar el estado de fusión de los elementos, su tamaño y correspondencia bilateral, su coloración y modificaciones de la superficie cortical, indican que todos los especímenes de puma corresponden a un mismo individuo.

Los vertebrados pequeños representan un bajo porcentaje del conjunto, pero exhiben mayor diversidad taxonómica. Entre los taxones identificados se incluyen peces, anfibios, reptiles, aves y mamíferos (Tabla 1). Dentro de esta última clase, que es la más abundante, predominan los especímenes de roedores, siendo la vizcacha (Lagostomus maximus) la especie mejor representada (NISP\% $=2,1$ ). Los restos de armadillo también son frecuentes, en particular de peludo (Chaetophractus villosus) (NISP\% $=0,9$ ). Si bien las placas dérmicas no fueron consideradas en el cálculo de la abundancia taxonómica relativa, se registran en gran número y a través de ellas se pudo identificar la presencia de otras dos especies de armadillo en el conjunto: piche (Zaedyus pichiy) y mulita (Dasypus hybridus).

\section{Características de la muestra de guanaco}

Como se mencionó con anterioridad, el guanaco es la especie más abundante en el sitio. Los especímenes de este camélido proceden en su mayoría de la UIII (NISP $=405$ ), aunque un pequeño número fue recuperado en el sector de contacto entre 


\begin{tabular}{|c|c|c|}
\hline Taxón & NISP & NISP\% \\
\hline Gastrópoda (terrestre) & (5) & - \\
\hline Perciformes & 1 & 0,1 \\
\hline Anura & 7 & 0,6 \\
\hline Reptilia & 1 & 0,1 \\
\hline Ophidia & 5 & 0,5 \\
\hline Ave indet & 9 & 0,8 \\
\hline Rheidae & (1) & - \\
\hline Rhea americana & 3 & 0,3 \\
\hline Mammalia pequeño & 36 & 3,3 \\
\hline Mammalia grande & 151 & 13,7 \\
\hline Mammalia indet. & 171 & 15,5 \\
\hline Ungulata & 103 & 9,4 \\
\hline Lama guanicoe & 405 & 36,8 \\
\hline Ozotoceros bezoarticus & 5 & 0,5 \\
\hline Canidae & 9 & 0,8 \\
\hline Puma concolor & 89 & 8,1 \\
\hline Rodentia & 19 & 1,7 \\
\hline Dolichotis patagonum & 2 & 0,2 \\
\hline Lagostomus maximus & 22 & 2,0 \\
\hline Myocastor coypus & 1 & 0,1 \\
\hline Caviidae & 2 & 0,2 \\
\hline Cavia aperea & 1 & 0,1 \\
\hline Ctenomys sp. & 8 & 0,7 \\
\hline Cricetidae & 3 & 0,3 \\
\hline Dasipodidae & $37(925)$ & 3,4 \\
\hline Chaetophractus villosus & $10(147)$ & 0,9 \\
\hline Zaedyus pichiy & (189) & - \\
\hline Dasypus hybridus & (5) & - \\
\hline Total NISP & $1.100(1.272)$ & \\
\hline Indeterminado pequeño & 159 & \\
\hline Indeterminado grande & 345 & \\
\hline Indeterminado & 6.425 & \\
\hline Total NSP & 9.301 & \\
\hline
\end{tabular}

Tabla 1. Representación taxonómica en la UIII del sitio LB3. Los valores entre paréntesis corresponden a placas dérmicas, fragmentos de valva y cáscara de huevo.

esta unidad y la unidad IV (NISP $=24$ ). La recomposición de la totalidad de los especímenes de guanaco permitió estimar un MNE de 266, incluyendo 228 elementos óseos (considerando al elemento completo) y 38 piezas dentales aisladas.

Como se observa en la Tabla 2, en el sitio ha sido recuperado un amplio espectro de unidades anatómicas de guanaco que corresponden a toda la carcasa. Los elementos del esqueleto apendicular ( $\mathrm{MNE}=130 ; 59 \%$; sin incluir sesamoideos) son más abundantes que los del axial ( $\mathrm{MNE}=90 ; 41 \%$; excluyendo las piezas dentales), mientras que los elementos de ambas extremidades se presentan en proporciones similares ( $49 \%$ 


\begin{tabular}{|c|c|c|c|c|c|c|c|c|c|c|c|c|c|c|c|c|}
\hline \multirow{2}{*}{ Elemento } & \multicolumn{4}{|c|}{ No fusionado } & \multicolumn{4}{|c|}{ Fusionado } & \multicolumn{4}{|c|}{ Fusión ND } & \multirow{2}{*}{ MNI } & \multirow{2}{*}{ MNE } & \multirow{2}{*}{ MAU } & \multirow{2}{*}{ MAU\% } \\
\hline & $\mathbf{I}$ & D & A & ND & 1 & D & $\mathrm{A}$ & ND & $I$ & D & A & ND & & & & \\
\hline Cráneo & - & - & - & - & - & - & 1 & - & - & - & 1 & - & 2 & 2 & 2 & 44,4 \\
\hline Mandíbula & - & - & - & - & - & - & 3 & - & - & - & - & - & 3 & 3 & 3 & 66,7 \\
\hline Hioides & - & - & - & - & - & - & - & - & - & - & 1 & - & 1 & 1 & 1 & 22,2 \\
\hline Incisivo & - & - & - & - & - & - & - & - & 5 & 2 & - & - & - & 7 & - & - \\
\hline Canino & - & - & - & - & - & - & - & - & - & 1 & - & 6 & - & 7 & - & - \\
\hline Premolar & - & - & - & - & - & - & - & - & 3 & 1 & & 2 & - & 6 & - & - \\
\hline Molar & - & - & - & - & - & - & - & - & 9 & 9 & - & - & - & 18 & - & - \\
\hline V. atlas & - & - & - & - & - & - & 2 & - & - & - & - & - & 2 & 2 & 2 & 44,4 \\
\hline V. cervical & - & - & 2 & - & - & - & 3 & - & - & - & - & - & 2 & 5 & 1 & 22,2 \\
\hline V. torácica & - & - & 8 & - & - & - & 9 & - & - & - & - & - & 2 & 17 & 1,42 & 31,6 \\
\hline V. lumbar & - & - & 1 & - & - & - & 10 & - & - & - & - & - & 2 & 11 & 1,57 & 34,9 \\
\hline Sacro & - & - & 1 & - & - & - & 1 & - & - & - & 1 & - & 3 & 3 & 3 & 66,7 \\
\hline V. caudal & - & - & - & - & - & - & 9 & - & - & - & - & - & 1 & 9 & - & - \\
\hline V. indet & - & - & 6 & - & - & - & 3 & - & - & - & 1 & - & 2 & 10 & - & - \\
\hline Costilla & - & - & - & - & 8 & 7 & - & 2 & 1 & - & - & 1 & 1 & 19 & 0,79 & 17,6 \\
\hline Esternebra & - & - & - & - & - & - & - & - & - & - & 1 & - & 1 & 1 & 0,17 & 3,8 \\
\hline Escápula & - & - & - & - & 2 & 2 & - & - & - & - & - & - & 2 & 4 & 2 & 44,4 \\
\hline Húmero px & - & - & - & 1 & 1 & 1 & - & - & - & - & - & 1 & 2 & 4 & 2 & 44,4 \\
\hline Húmero df & 2 & - & - & - & 4 & 3 & - & - & - & - & - & - & 6 & 9 & 4,5 & 100 \\
\hline Húmero ds & - & - & - & - & 4 & 2 & - & - & - & 1 & - & - & 4 & 7 & 3,5 & 77,8 \\
\hline Radio-ulna px & - & - & - & - & 2 & 1 & - & - & - & - & - & - & 2 & 3 & 1,5 & 33,3 \\
\hline Radio-ulna df & 1 & - & - & - & 1 & 2 & - & - & - & - & - & - & 2 & 4 & 2 & 44,4 \\
\hline Radio-ulna ds & - & 1 & - & - & 1 & 2 & - & - & 1 & - & - & - & 3 & 5 & 2,5 & 55,6 \\
\hline Escafoide & - & - & - & - & - & - & - & - & 3 & 2 & - & - & 3 & 5 & 2,5 & 55,6 \\
\hline Lunar & - & - & - & - & - & - & - & - & 2 & 1 & - & - & 2 & 3 & 1,5 & 33,3 \\
\hline Cuneiforme & - & - & - & - & - & - & - & - & 2 & - & - & - & 2 & 2 & 1 & 22,2 \\
\hline Trapezoide & - & - & - & - & - & - & - & - & 2 & 2 & - & - & 2 & 4 & 2 & 44,4 \\
\hline Magnum & - & - & - & - & - & - & - & - & 2 & 3 & - & 1 & 3 & 6 & 3 & 66,7 \\
\hline Unciforme & - & - & - & - & - & - & - & - & 1 & 2 & - & - & 2 & 3 & 1,5 & 33,3 \\
\hline Pisiforme & - & - & - & - & - & - & - & - & 1 & 1 & - & - & 1 & 2 & 1 & 22,2 \\
\hline Metacarpo px & - & - & - & - & 1 & 1 & - & - & 1 & 3 & - & - & 4 & 6 & 3 & 66,7 \\
\hline Metacarpo df & - & - & - & - & 1 & 1 & - & - & 1 & 1 & - & - & 2 & 4 & 2 & 44,4 \\
\hline Metacarpo ds & - & - & - & - & 1 & 1 & - & - & - & - & - & - & 1 & 2 & 1 & 22,2 \\
\hline Hemipelvis & - & 1 & - & - & 1 & 4 & - & - & 1 & - & - & - & 5 & 7 & 3,5 & 77,8 \\
\hline Fémur px & 1 & - & - & - & 2 & 2 & - & - & - & - & - & 1 & 3 & 6 & 3 & 66,7 \\
\hline Fémur df & 1 & 1 & - & - & 4 & 2 & - & - & - & - & - & - & 5 & 8 & 4 & 88,9 \\
\hline Fémur ds & - & - & - & - & 2 & 1 & - & - & - & 1 & - & - & 2 & 4 & 2 & 44,4 \\
\hline Patella & - & - & - & - & - & - & - & - & 1 & 1 & - & - & 1 & 2 & 1 & 22,2 \\
\hline Tibia px & 1 & - & - & - & 3 & 2 & - & - & - & - & - & - & 4 & 6 & 3 & 66,7 \\
\hline Tibia df & - & - & - & - & 3 & 2 & - & - & - & 2 & - & - & 4 & 7 & 3,5 & 77,8 \\
\hline Tibia ds & 1 & - & - & - & 4 & 2 & - & - & - & - & - & - & 5 & 7 & 3,5 & 77,8 \\
\hline Calcáneo & - & - & - & - & 4 & 3 & - & - & 1 & - & - & - & 5 & 8 & 4 & 88,9 \\
\hline Astrágalo & - & - & - & - & - & - & - & - & 2 & 2 & - & - & 2 & 4 & 2 & 44,4 \\
\hline Fibular & - & - & - & - & - & - & - & - & 1 & 2 & - & - & 2 & 3 & 1,5 & 33,3 \\
\hline
\end{tabular}




\begin{tabular}{|l|c|c|c|c|c|c|c|c|c|c|c|c|c|c|c|c|}
\hline \multirow{2}{*}{ Elemento } & \multicolumn{4}{|c|}{ No fusionado } & \multicolumn{3}{|c|}{ Fusionado } & \multicolumn{3}{|c|}{ Fusión ND } & \multirow{2}{*}{ MNE } & \multirow{2}{*}{ MAU } & \multirow{2}{*}{ MAU\% } \\
\cline { 2 - 3 } & I & D & A & ND & I & D & A & ND & I & D & A & ND & & & \\
\hline Navicular & - & - & - & - & - & - & - & - & 2 & 1 & & 1 & 2 & 4 & 2 & 44,4 \\
\hline 1er. Tarsiano & - & - & - & - & - & - & - & - & & - & - & 2 & 1 & 2 & 1 & 22,2 \\
\hline Ectocuneiforme & - & - & - & - & - & - & - & - & 1 & 3 & - & - & 3 & 4 & 2 & 44,4 \\
\hline Cuboide & - & - & - & - & - & - & - & - & 3 & 1 & - & - & 3 & 4 & 2 & 44,4 \\
\hline Metatarso px & - & - & - & - & 1 & 1 & - & - & 1 & 1 & - & - & 2 & 4 & 2 & 44,4 \\
\hline Metatarso df & - & - & - & - & 1 & 1 & - & - & 1 & 1 & - & - & 2 & 4 & 2 & 44,4 \\
\hline Metatarso ds & - & - & - & - & 1 & 1 & - & - & - & - & - & - & 1 & 2 & 1 & 22,5 \\
\hline Metapodio df & - & - & - & 3 & - & - & - & 3 & - & - & - & - & 2 & 6 & 1,5 & 33,3 \\
\hline Metapodio ds & - & - & - & 3 & - & - & - & 7 & - & - & - & - & 3 & 10 & 2,5 & 55,6 \\
\hline Falange 1 & - & - & - & - & - & - & - & 11 & - & - & - & - & 2 & 11 & 1,38 & 30,7 \\
\hline Falange 2 & - & - & - & - & - & - & - & 7 & - & - & - & - & 1 & 7 & 0,88 & 19,6 \\
\hline Falange 3 & - & - & - & - & - & - & - & - & - & - & - & 7 & 1 & 7 & 0,88 & 19,6 \\
\hline Sesamoideo & - & - & - & - & - & - & - & - & - & - & - & 8 & - & 8 & - & - \\
\hline
\end{tabular}

Tabla 2. Representación anatómica de guanaco -Lama guanicoe- en LB3. Referencias: I: izquierda; D: derecha; A: axial; ND: no determinada; px: proximal; df: diáfisis; ds: distal.

elementos del miembro delantero y $50 \%$ del miembro trasero; excluyendo metapodios indeterminados y falanges). El leve predominio de la epífisis distal en relación con la proximal del húmero y la tibia sugiere la ocurrencia de procesos de destrucción diferencial mediados por la densidad ósea, aunque este sesgo no sería acentuado. Este último aspecto es apoyado por los datos surgidos del análisis tafonómico (ver abajo apartado Modificaciones tafonómicas), los cuales sugieren que los procesos destructivos, tales como la meteorización, la acción de carnívoros, la fragmentación antrópica y la alteración térmica, actuaron con baja intensidad sobre la muestra de vertebrados grandes. Asimismo, la comparación de la representación de partes con el modelo de transporte hídrico muestra que en el sitio se encuentran presentes tanto elementos de alto (Grupo 1) como de bajo (Grupo 3) potencial de transporte, para las tres clases de edad propuestas (Kaufmann et al., 2011). En el caso de los elementos que pudieron ser asignados a cría, se observa la presencia de un pubis (Grupo 1) y de las diáfisis de un radio y de una ulna (Grupo 3). Entre aquellos que corresponden a la categoría cría/juvenil, se registran una vértebra sacra y la cabeza de un húmero (Grupo 1) y las diáfisis de tres metapodios y dos fémures (Grupo 3). Por último, dentro de los elementos asignados a adulto, se observa un sacro y numerosas vértebras torácicas, lumbares y caudales (Grupo 1), así como un cráneo, tres mandíbulas, tres vértebras cervicales y numerosas costillas, falanges y huesos largos (Grupo 3) (Tabla 2).

El elemento más frecuente en el sitio es el húmero, el cual se encuentra bien representado por su porción distal. A partir de este elemento se estimó un MNI de seis guanacos, dos de ellos cría (menos de 12 meses de edad), de acuerdo al estado no fusionado de dos diáfisis distales a sus correspondientes epífisis (centro de osificación H5 en Kaufmann, 2009). Asimismo, observaciones preliminares del material dentario sugieren la presencia de un individuo juvenil/subadulto y de tres individuos adultos.

\section{Modificaciones tafonómicas}

El análisis tafonómico fue realizado sobre un total de 918 especímenes de vertebrados grandes y 332 de vertebrados pequeños recuperados en la UIII. En la Tabla 3 se muestra la representación porcentual de las variables tafonómicas para cada una de las muestras. 


\begin{tabular}{|c|c|c|c|}
\hline \multicolumn{2}{|l|}{ Variable tafonómica } & \multirow{2}{*}{$\begin{array}{c}\begin{array}{c}\text { Vertebrados } \\
\text { grandes }\end{array} \\
65,4\end{array}$} & \multirow{2}{*}{$\begin{array}{c}\begin{array}{c}\text { Vertebrados } \\
\text { pequeños }\end{array} \\
64,2\end{array}$} \\
\hline Meteorización & Estadio o & & \\
\hline & Estadio 1 & 18,7 & 27 \\
\hline & Estadio 2 & 9,7 & 7,6 \\
\hline & Estadio 3 & 5,1 & 1,2 \\
\hline & Estadio 4 & 1 & - \\
\hline & Estadio 5 & 0,2 & - \\
\hline \multirow[t]{5}{*}{ Abrasión geológica } & Ausente & 55,9 & 8,4 \\
\hline & Estadio 1 & 25,9 & 29,8 \\
\hline & Estadio 2 & 9,6 & 40,1 \\
\hline & Estadio 3 & 1,5 & 6 \\
\hline & Estadio 2-3 & 7,1 & 15,7 \\
\hline \multicolumn{2}{|l|}{ Carbonato de calcio } & 0,3 & 19,9 \\
\hline \multicolumn{2}{|l|}{ Manganeso } & 19,1 & 36,7 \\
\hline \multicolumn{2}{|l|}{ Deterioro químico } & 7,6 & 27,1 \\
\hline \multicolumn{2}{|l|}{ Raíces } & 16,3 & 22,3 \\
\hline \multicolumn{2}{|l|}{ Marcas de roedor } & 17,6 & 1,2 \\
\hline \multicolumn{2}{|l|}{ Marcas de carnívoro } & 1,7 & 0,9 \\
\hline \multicolumn{2}{|l|}{ Digestión gástrica } & - & 0,3 \\
\hline \multicolumn{2}{|l|}{ Pisoteo } & 10,2 & 9,3 \\
\hline \multicolumn{2}{|l|}{ Alteración térmica } & 2,9 & 10,8 \\
\hline \multicolumn{2}{|l|}{ Huellas de corte } & 3,3 & 1,2 \\
\hline \multicolumn{2}{|l|}{ Marcas de percusión } & 2,6 & - \\
\hline \multicolumn{2}{|l|}{ Presencia de fractura } & 85 & 87,7 \\
\hline \multirow{3}{*}{$\begin{array}{l}\text { Estado del hueso } \\
\text { al momento de la } \\
\text { fractura }\end{array}$} & Seco & 52,6 & 72,0 \\
\hline & Fresco & 28,7 & 7,0 \\
\hline & No determinado & 18,7 & 21,0 \\
\hline
\end{tabular}

Tabla 3. Representación porcentual de las distintas variables tafonómicas para las muestras de vertebrados grandes y vertebrados pequeños de la UIII.

Los perfiles de meteorización son similares en ambos conjuntos, con un predominio de especímenes en estadios 0 y 1 . Con mayor frecuencia se registra la abrasión geológica, en un $44 \%$ de los restos de vertebrados grandes (la mayoría en estadio 1) y en un $92 \%$ de los restos de vertebrados pequeños (predominio del estadio 2).

Las manchas de óxido de manganeso, las concreciones de óxido de hierro, el grabado por raíces y el deterioro químico también son frecuentes en ambas muestras (Tabla 3). Otra variable tafonómica bien representada son las marcas de pisoteo, con un porcentaje cercano al $10 \%$ en ambos conjuntos.

Por otro lado, en la muestra de vertebrados grandes son más frecuentes las marcas de roedores y carnívoros (Figura 4). Estas últimas se registraron sobre 12 especímenes de guanaco (dos de los cuales presentan también huellas de corte), uno de venado de las pampas y tres de vertebrados grandes no identificados. En cuanto a los vertebrados pequeños, se reconocieron marcas de carnívoro sobre dos especímenes de vizcacha y uno de ave indeterminada, así como digestión gástrica en otro espécimen de ave indeterminada. 

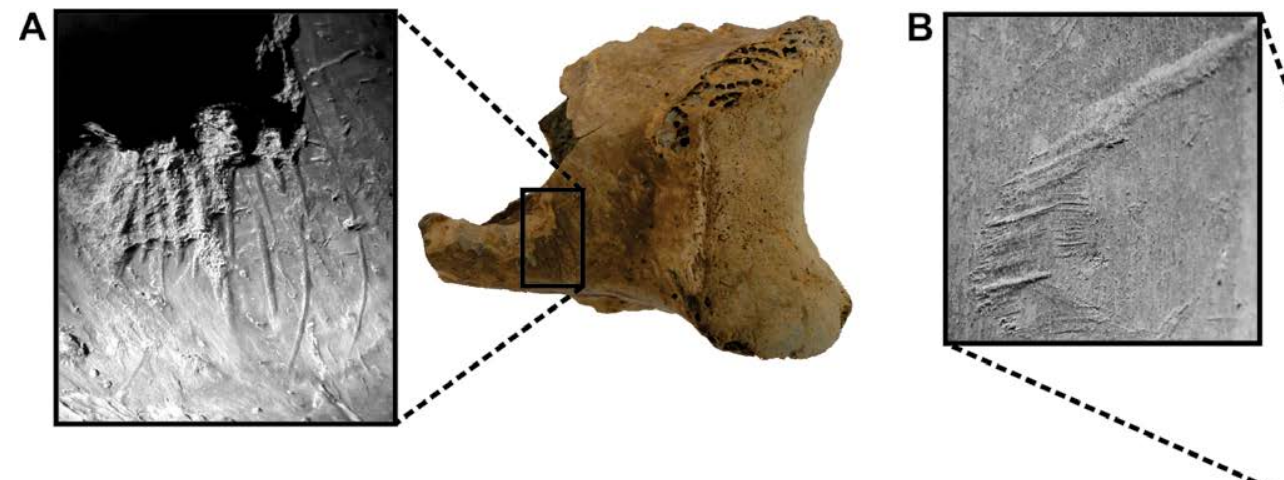

C

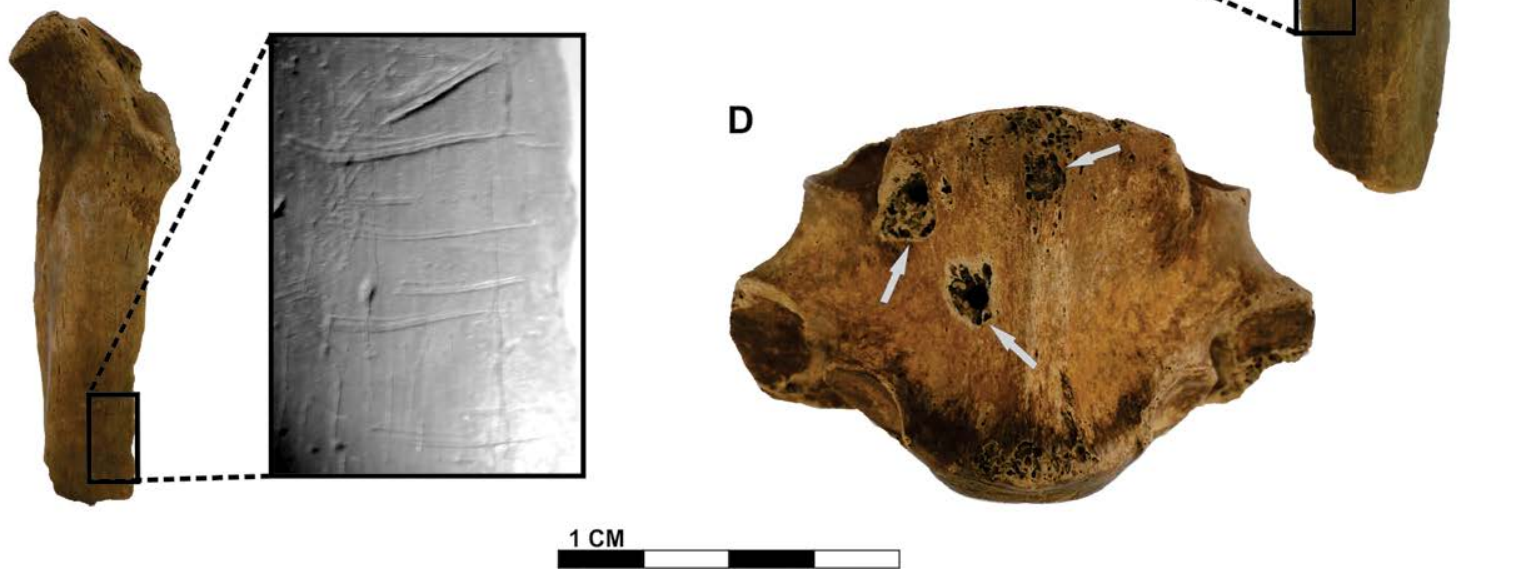

Figura 4. Modificaciones óseas observadas en el conjunto faunístico del sitio LB3. Referencias: A: tibiotarso distal de ñandú -Rhea americanacon huellas de corte y marcas de roedor superpuestas (FCS.LB3.599); B: fragmento de metatarso proximal de guanaco -Lama guanicoe- con estrías de percusión sobre el borde de fractura (FCS.LB3.443); C: fragmento proximal de costilla de guanaco con huellas de corte (FCS.

LB3.461); D: vista ventral de vértebra torácica de guanaco con perforaciones por carnívoro (FCS.LB3.534).

La alteración térmica se observa en restos de ambas clases de vertebrado, aunque es más frecuente entre los pequeños, donde afecta cerca del 11\% de la muestra. Esta modificación se registró en cinco especímenes de vizcacha (incluyendo tres astrágalos derechos), uno de coypo, uno de peludo, uno de cánido y 29 de mamíferos y vertebrados pequeños indeterminados. Asimismo, es importante mencionar que 94 placas dérmicas de armadillo presentan termoalteración (7,4\% de las placas recuperadas en la UIII). Catorce de éstas corresponden a piche y siete a peludo, mientras que las restantes solo pudieron ser determinadas como Dasipodidae. En el caso de los vertebrados grandes, la alteración térmica se presenta en cuatro especímenes de guanaco (cavidad glenoidea de escápula, acetábulo de hemipelvis, diáfisis de tibia y diáfisis de metapodio) y en 23 fragmentos asignados a mamíferos o vertebrados indeterminados.

Con respecto a las evidencias de procesamiento antrópico, se identificaron huellas de corte en 3,3\% de los restos de vertebrados grandes y en 1,2\% de los de vertebrados pequeños. En cuanto a los primeros, se registraron sobre 20 especímenes de guanaco, tres de ñandú, uno de mamífero grande y seis de vertebrado grande (Figura 4); en cuanto a los segundos, sobre uno de armadillo, uno de ave indeterminada (tamaño similar a tinámidos) y dos de vertebrado pequeño. Además, se reconocieron huellas de corte sobre 10 placas dérmicas de armadillo, dos de las cuales pudieron ser asignadas a peludo.

La proporción de huesos fracturados es alta en ambas muestras (85\% en vertebrados grandes y $88 \%$ en vertebrados pequeños). En la muestra de huesos largos y falange 
proximal de vertebrados grandes $(n=272)$, se determinó que un $28,7 \%$ de los especímenes se fracturó en estado fresco y un $52,6 \%$ en estado seco, mientras que en un $18,7 \%$ de los casos esta condición no pudo ser determinada. Además en un $32 \%$ de los especímenes fracturados en estado fresco se identificaron evidencias que indican el origen antrópico de la fractura (i.e., puntos de impacto, negativos de lascado, marcas de percusión) (Figura 4). Estos especímenes corresponden a guanaco $(\mathrm{n}=13)$, venado de las pampas $(\mathrm{n}=1)$, ñandú $(\mathrm{n}=2)$ y mamíferos y vertebrados grandes indeterminados $(n=9)$. Por otra parte, en la muestra de vertebrados chicos $(\mathrm{n}=57)$, un $7 \%$ de las fracturas fue clasificada como fresca, un $72 \%$ como seca y un $21 \%$ como no determinada.

\section{Conjunto lítico}

En el conjunto lítico recuperado en LB3 $(n=760)$ predominan ampliamente los desechos de talla (95,5\%), seguidos por los instrumentos (4,3\%); mientras que solo se recuperó un núcleo. En cuanto a las materias primas, se observa la explotación preferencial de OGSB $(93,6 \%)$. En muy baja frecuencia se utilizaron otras materias primas, como ftanita $(3,9 \%)$, toba silicificada $(1,2 \%)$, roca granitoide $(0,7 \%)$, sílice $(0,3 \%)$, cuarzo y esquisto micáceo $(0,1 \%$ cada una). Por su parte, la presencia de corteza se registra en un bajo porcentaje de los artefactos $(2,1 \%)$, incluyendo un núcleo y 14 desechos de talla de OGSB y un desecho de ftanita.

\section{Artefactos de OGSB}

El único núcleo recuperado fue tallado en OGSB y presenta remanentes de corteza (menos del $20 \%$ de su superficie). Es de tamaño pequeño ( 71 grs) y forma piramidal irregular (Figura 5). Fue confeccionado sobre una lasca y se utilizó su cara ventral como plataforma de percusión. Presenta siete negativos de lascado en los que se observa la boca de extracción y un negativo previo sin boca de extracción visible.

La OGSB fue empleada para la manufactura de diversos tipos de instrumentos por medio de lascados $(\mathrm{n}=27)$, siendo los más frecuentes los compuestos y las raederas (Tabla 4; Figura 5). Un alto porcentaje de los instrumentos se encuentra fracturado $(77,8 \%)$. En cuanto a las formas base, predominan las lascas extraídas por percusión directa, principalmente angulares; aunque también se registran lascas bipolares. Entre los instrumentos enteros y los fracturados que conservan más del $90 \%$ de la pieza original, predominan los tamaños mediano grande y mediano pequeño, los módulos longitud-anchura laminar normal, mediano alargado y mediano normal y el módulo anchura-espesor espeso. La mayoría de los instrumentos son unifaciales (la única excepción es un instrumento con filos alternos) y presentan bajo grado de modificación: en general se observa el empleo de microretoques y retoques marginales para la conformación de filos o puntas.

Con respecto a los desechos de talla $(n=683)$, se observa un predominio de las lascas fracturadas, con y sin talón, seguidas por las lascas enteras y los desechos indiferenciados (Tabla 5). Entre las lascas predominan las angulares, las indiferenciadas, las de arista y las planas; además se han identificado lascas de reactivación directa, secundarias, de dorso natural, bipolares, de reactivación indirecta, de adelgazamiento, primarias y de reactivación de núcleo. En las lascas que conservan el talón, se observa que el tipo más frecuente es el liso. Por último, entre las enteras se observa una mayor representación del tamaño muy pequeño, del módulo longitud-anchura mediano normal y del módulo anchura-espesor poco espeso. 


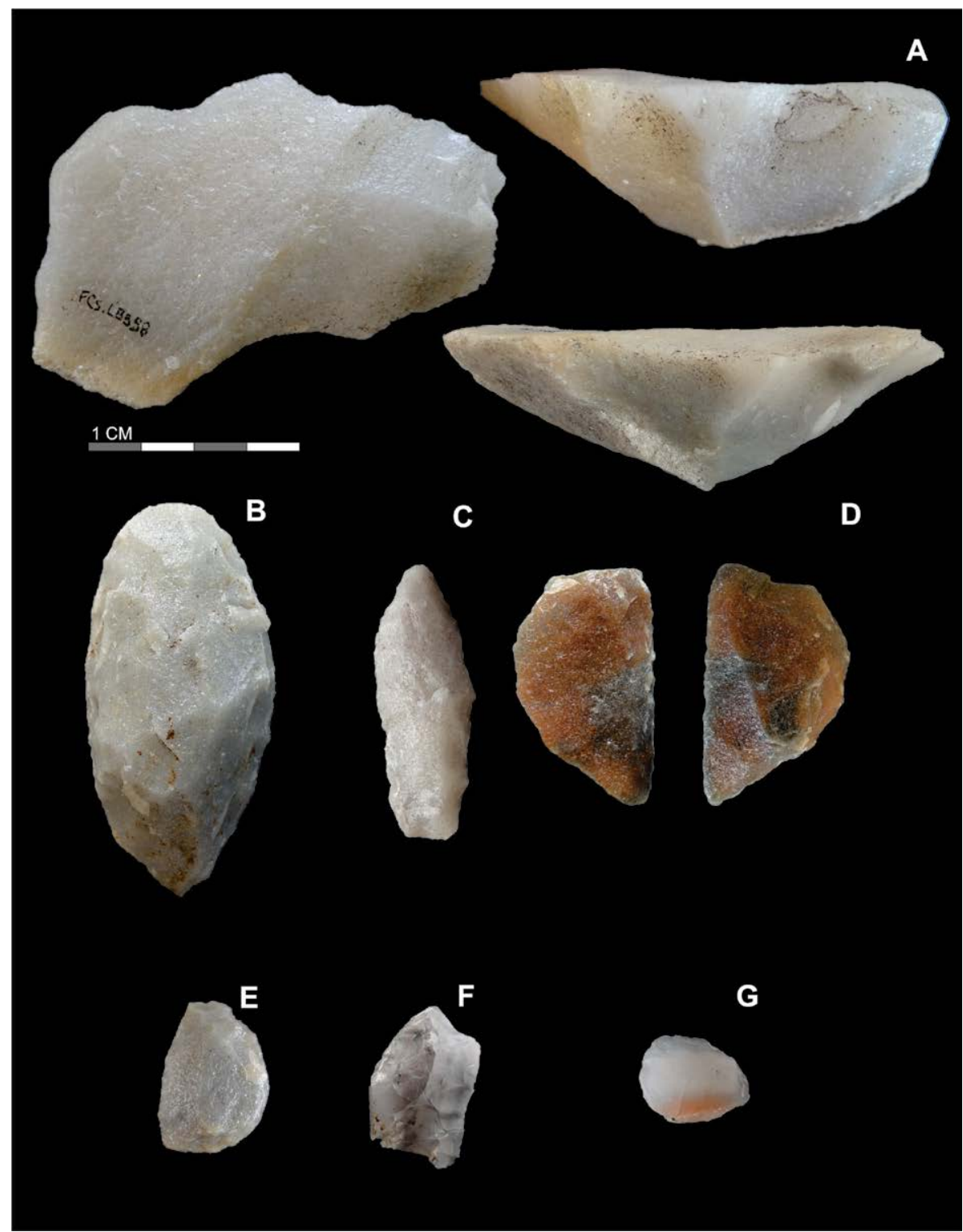

Figura 5. Artefactos líticos del sitio LB3. Referencias: A: núcleo piramidal irregular en ortocuarcita del Grupo Sierras Bayas -OGSB-, vista de la plataforma y frentes de extracción (FCS.LB3.58); B-C: raederas de filos dobles convergentes en OGSB (FCS.LB3.73 y FCS.LB3.75); D: instrumento compuesto de filos alternos en OGSB (FCS.LB3.101); E: instrumento compuesto en OGSB (FCS.LB3.7); F: raspador lateral corto en ftanita (FCS.LB3.35); G: raspador fronto-bilateral en ftanita (FCS.LB3.4001).

\section{Artefactos de ftanita}

Los artefactos de ftanita consisten en cuatro instrumentos y 26 desechos de talla. Entre los primeros, se registran dos raspadores (Figura 5) y un instrumento compuesto (todos fragmentados), así como un fragmento no diferenciado de artefacto formatizado (Tabla 4). Todos ellos fueron elaborados sobre lascas mediante microretoques y retoques marginales en situación unifacial directa.

En cuanto a los desechos de talla (Tabla 5), predominan las lascas enteras, seguidas por las lascas fracturadas con y sin talón. La mayoría de las lascas son de tipo angular, de tamaño muy pequeño, de módulo anchura-espesor poco espeso y presentan gran variabilidad en cuanto al módulo longitud-anchura. El tipo de talón más representado es el liso. 


\begin{tabular}{|c|c|c|c|c|c|}
\hline & OGSB & FTA & TBS & IN & Total \\
\hline Grupo tipológico & & & & & \\
\hline Cuchillo & 2 & & & & 2 \\
\hline Filo bisel asimétrico & 3 & & & & 3 \\
\hline Instrumento compuesto & 6 & 1 & & & 7 \\
\hline Pieza con retoque sumario & 1 & & & & 1 \\
\hline Punta destacada & 2 & & & & 2 \\
\hline Raedera & 5 & & & & 5 \\
\hline Raspador & & 2 & & & 2 \\
\hline Fragmento instrumento molienda & & & & 1 & 1 \\
\hline FND & 8 & 1 & 1 & & 10 \\
\hline Estado & & & & & \\
\hline Entero & 6 & & & & 6 \\
\hline Fragmentado & 6 & 3 & & & 9 \\
\hline Fragmento & 15 & 1 & 1 & 1 & 18 \\
\hline Forma base & & & & & \\
\hline Lasca angular & 6 & 1 & & & 7 \\
\hline Lasca de arista & 3 & & & & 3 \\
\hline Lasca de tableta de núcleo & 1 & & & & 1 \\
\hline Lasca bipolar & 2 & 1 & & & 3 \\
\hline Hoja de arista simple & 1 & & & & 1 \\
\hline Lasca no diferenciada & 14 & 2 & & & 16 \\
\hline No diferenciada & & & 1 & 1 & 2 \\
\hline Tamaño & & & & & \\
\hline Pequeño & 1 & 2 & & & 3 \\
\hline Mediano pequeño & 4 & 1 & & & 5 \\
\hline Mediano grande & 6 & & & & 6 \\
\hline Grande & 1 & & & & 1 \\
\hline Módulo longitud-anchura & & & & & \\
\hline Laminar normal & 4 & & & & 4 \\
\hline Mediano alargado & 3 & 1 & & & 4 \\
\hline Mediano normal & 4 & 1 & & & 5 \\
\hline Corto ancho & & 1 & & & 1 \\
\hline Corto muy ancho & 1 & & & & 1 \\
\hline Módulo anchura-espesor & & & & & \\
\hline Poco espeso & 1 & 1 & & & 2 \\
\hline Espeso & 8 & 1 & & & 9 \\
\hline Muy espeso & 3 & 1 & & & 4 \\
\hline
\end{tabular}

Tabla 4. Características tecnomorfológicas de los instrumentos recuperados en LB3.

Referencias: OGSB: ortocuarcita del Grupo Sierras Bayas; FTA: ftanita; TBS: toba silicificada; IN: materia prima indeterminada; FND: fragmento no diferenciado de artefacto formatizado. 


\section{Artefactos de otras materias primas}

Un número reducido de artefactos fue elaborado sobre toba silicificada, entre ellos un instrumento -del cual solo se conserva un fragmento de filo unifacial- (Tabla 4) y ocho desechos de talla. Estos últimos son en su mayoría lascas angulares de tamaño muy pequeño (Tabla 5).

Los restantes artefactos manufacturados sobre materias primas aún menos frecuentes son: un fragmento de instrumento pasivo de molienda sobre una roca no identificada, cinco desechos indiferenciados sobre rocas granitoides y uno sobre esquisto micáceo, una lasca de reactivación directa sobre sílice (posiblemente chert silíceo), una lasca indiferenciada sobre una roca silícea no identificada y una lasca angular de cuarzo (Tablas 4 y 5 ).

\section{Discusión}

Las evidencias arqueológicas del sitio LB3 se encuentran contenidas en un depósito sedimentario de origen fluvio-lacustre sobre el cual se desarrolló un paleosuelo palustre de carácter cumúlico. Este depósito representa las márgenes de un cuerpo de agua somero (i.e. charca o laguna poco profunda) que habría existido en el lugar que actualmente ocupa la planicie de inundación del arroyo Cristiano Chico. Los cambios sedimentológicos y el desarrollo del paleosuelo en el tope de este depósito parecen estar indicando la somerización de este cuerpo de agua. La información cronológica de los cuatro sitios de la localidad indica que los grupos humanos ocuparon de manera recurrente, aunque con baja intensidad, este entorno acuático, posiblemente desde el Holoceno medio (sitio LB4) y durante la primer parte del Holoceno tardío (sitios LB1, LB2 y LB3). En el caso particular del sitio LB3, el único fechado obtenido hasta el momento permite plantear la ocurrencia de al menos un evento de ocupación humana hace unos 2800 años ${ }^{14} \mathrm{C}$ AP.

\section{Historia tafonómica del conjunto faunístico}

El análisis faunístico permite proponer a los humanos como los principales responsables, pero no únicos, de la depositación de restos faunísticos en el sitio LB3. En este sentido, se plantea que la incorporación de huesos de puma al depósito se produjo como consecuencia de la muerte natural de un individuo in situ en momentos posteriores a las ocupaciones humanas. Este argumento se basa en las siguientes evidencias: los huesos corresponden todos a un mismo individuo, la mayoría de ellos se hallaban agrupados en un sector acotado del área excavada en niveles de excavación con muy escasa presencia de otros materiales -tales como artefactos líticos- y no se observaron modificaciones antrópicas sobre los huesos.

La identificación de alteraciones por carnívoro en restos de distintos taxones indica que este agente también pudo haber contribuido a la acumulación y modificación del conjunto faunístico. Los predadores pudieron haber carroñado huesos descartados por los humanos (e.g. guanaco) así como incorporado al depósito huesos de presas obtenidas fuera del sitio como resultado de la depositación de egagrópilas por aves rapaces o fecas por carnívoros (e.g. hueso de ave con digestión).

Las evidencias de meteorización en el conjunto indican que los restos estuvieron expuestos a las condiciones atmosféricas antes de ser sepultados por los sedimentos. Sin embargo, el bajo porcentaje de restos meteorizados y el predominio de los estadios más bajos muestran que este proceso no habría afectado de modo significativo la preservación de ninguna de las muestras de vertebrados. 


\begin{tabular}{|c|c|c|c|c|c|c|c|c|c|c|}
\hline \multirow{2}{*}{\multicolumn{2}{|c|}{ Variables tecno-morfológicas }} & \multicolumn{7}{|c|}{ Materias primas } & \multicolumn{2}{|c|}{ Total } \\
\hline & & OGSB & FTA & TBS & CZL & SIL & GRA & ESQ & $\mathbf{N}$ & $\%$ \\
\hline $\begin{array}{l}\text { Estado } \\
(n=726)\end{array}$ & $\begin{array}{l}\text { LENT } \\
\text { LFCT } \\
\text { LFST } \\
\text { DNC }\end{array}$ & $\begin{array}{l}129 \\
227 \\
203 \\
124\end{array}$ & $\begin{array}{l}10 \\
7 \\
7 \\
2\end{array}$ & $\begin{array}{l}2 \\
5 \\
1\end{array}$ & 1 & 1 & 5 & 1 & $\begin{array}{l}143 \\
239 \\
212 \\
132\end{array}$ & $\begin{array}{l}19,70 \\
32,92 \\
29,20 \\
18,18\end{array}$ \\
\hline $\begin{array}{l}\text { Tipo de lasca } \\
(\mathrm{n}=594)\end{array}$ & $\begin{array}{l}\text { Primaria } \\
\text { Secundaria } \\
\text { Con dorso natural } \\
\text { Angular } \\
\text { De arista } \\
\text { Plana } \\
\text { De adelgazamiento } \\
\text { De reactivación directa } \\
\text { De reactivación indirecta } \\
\text { De reacticación de núcleo } \\
\text { Bipolar } \\
\text { Indiferenciada }\end{array}$ & $\begin{array}{c}1 \\
6 \\
3 \\
259 \\
70 \\
68 \\
2 \\
16 \\
2 \\
1 \\
2 \\
129\end{array}$ & 1 & 1 & 1 & 1 & & & $\begin{array}{c}1 \\
6 \\
3 \\
284 \\
70 \\
69 \\
2 \\
19 \\
2 \\
1 \\
2 \\
135\end{array}$ & $\begin{array}{l}0,17 \\
1,01 \\
0,51 \\
47,81 \\
11,78 \\
11,62 \\
0,34 \\
3,20 \\
0,34 \\
0,17 \\
0,34 \\
22,73\end{array}$ \\
\hline $\begin{array}{l}\text { Tipo de talón } \\
(\mathrm{n}=382)\end{array}$ & $\begin{array}{l}\text { Cortical } \\
\text { Liso } \\
\text { Filiforme } \\
\text { Puntiforme } \\
\text { Astillado } \\
\text { Fracturado } \\
\text { Diedro } \\
\text { Facetado }\end{array}$ & $\begin{array}{c}1 \\
181 \\
72 \\
27 \\
3 \\
42 \\
19 \\
11\end{array}$ & $\begin{array}{l}9 \\
1 \\
2\end{array}$ & $\begin{array}{l}3 \\
1 \\
1\end{array}$ & 1 & 1 & & & $\begin{array}{c}1 \\
194 \\
74 \\
30 \\
3 \\
50 \\
19 \\
11\end{array}$ & $\begin{array}{r}0,26 \\
50,79 \\
19,37 \\
7,85 \\
0,79 \\
13,09 \\
4,97 \\
2,88\end{array}$ \\
\hline $\begin{array}{l}\text { Tamaño } \\
(\mathrm{n}=143)\end{array}$ & $\begin{array}{l}\text { Muy pequeño } \\
\text { Pequeño } \\
\text { Mediano pequeño } \\
\text { Mediano grande } \\
\text { Grande } \\
\end{array}$ & $\begin{array}{l}89 \\
31 \\
5 \\
3 \\
1\end{array}$ & $\begin{array}{l}7 \\
3\end{array}$ & $\begin{array}{l}1 \\
1\end{array}$ & 1 & 1 & & & $\begin{array}{c}97 \\
37 \\
5 \\
3 \\
1\end{array}$ & $\begin{array}{l}67,83 \\
25,87 \\
3,50 \\
2,10 \\
0,70 \\
\end{array}$ \\
\hline $\begin{array}{l}\text { Módulo L-A } \\
(n=143)\end{array}$ & $\begin{array}{l}\text { Laminar normal } \\
\text { Mediano alargado } \\
\text { Mediano normal } \\
\text { Corto ancho } \\
\text { Corto muy ancho } \\
\text { Corto anchísimo }\end{array}$ & $\begin{array}{l}2 \\
13 \\
54 \\
34 \\
17 \\
9\end{array}$ & $\begin{array}{l}3 \\
4 \\
2 \\
1\end{array}$ & $\begin{array}{l}1 \\
1\end{array}$ & 1 & 1 & & & $\begin{array}{c}2 \\
16 \\
58 \\
38 \\
20 \\
9\end{array}$ & $\begin{array}{l}1,40 \\
11,19 \\
40,56 \\
26,57 \\
13,99 \\
6,29\end{array}$ \\
\hline $\begin{array}{l}\text { Módulo A-E } \\
(n=143)\end{array}$ & $\begin{array}{l}\text { Poco espeso } \\
\text { Espeso }\end{array}$ & $\begin{array}{c}100 \\
29\end{array}$ & $\begin{array}{l}7 \\
3\end{array}$ & 2 & 1 & 1 & & & $\begin{array}{c}110 \\
33\end{array}$ & $\begin{array}{l}76,92 \\
23,08\end{array}$ \\
\hline
\end{tabular}

Tabla 5. Características tecnomorfológicas de los desechos de talla recuperados en LB3. Referencias: OGSB: ortocuarcita del Grupo Sierras Bayas; FTA: ftanita; TBS: toba silicificada; CZL: cuarzo; SIL: sílice; GRA: granito; ESQ: esquisto; LENT: lasca entera; LFCT: lasca fracturada con talón; LFST: lasca fracturada sin talón; DNC: desecho no clasificable; L-A: longitud-anchura; A-E: anchura-espesor.

El alto porcentaje de especímenes que presentan abrasión geológica sugiere que una parte importante del conjunto faunístico estuvo sometido a la acción hídrica. Las características del ambiente sedimentario permiten vincular este proceso a episodios de inundación de la planicie, los mismos que contribuyeron al enterramiento de 
los restos. La granulometría fina del depósito indica dinámicas hídricas de baja energía, lo cual es coincidente con el predominio de estadios leves de abrasión en la muestra de vertebrados grandes y con la presencia de una gran diversidad de unidades anatómicas en la muestra de guanaco, incluso de aquellas con alto potencial de transporte por el agua (Kaufmann et al., 2011). Estos datos permiten sostener el origen principalmente autóctono del conjunto faunístico y la ocurrencia de procesos de abrasión mayormente in situ. La acción del agua sobre el conjunto luego de su depositación por los humanos pudo haber ocasionado el desplazamiento horizontal de algunos materiales, en especial de aquellos más susceptibles a la acción de este agente (e.g., huesos de pequeños vertebrados, epífisis no fusionadas de vertebrados grandes). Asimismo, pudo contribuir a la incorporación de restos de animales muertos naturalmente.

Otro proceso que actuó sobre el depósito, identificado a través de la presencia de marcas sobre la superficie cortical de los especímenes, fue el pisoteo. Este pudo contribuir a la fragmentación de los materiales faunísticos y líticos, a su desplazamiento vertical y, posiblemente también, a la abrasión de los restos (Eren et al., 2010; Olsen y Shipman, 1988).

Asimismo, el análisis tafonómico reveló que el conjunto faunístico fue afectado por los roedores y la vegetación. La perturbación del depósito por animales cavadores (e.g. armadillos) fue evidenciada también durante los trabajos de campo por la presencia de cuevas. La bioturbación por los animales cavadores y la vegetación pudo ser otro de los procesos que favoreció la dispersión vertical de los materiales arqueológicos y la fragmentación de los restos faunísticos (Frontini y Escosteguy, 2012; Wood y Johnson, 1978).

Por último, otras modificaciones tafonómicas frecuentes en ambas muestras de vertebrados son las precipitaciones de óxidos de manganeso y hierro así como el deterioro químico. Las características del ambiente de depositación permiten proponer que estas alteraciones son consecuencia principalmente de la fluctuación del nivel freático. Los cambios en el contenido de agua de un depósito provocan la alternancia de ciclos de oxidación y reducción, los cuales conducen a la precipitación sobre los huesos de manganeso y hierro transportados en solución por el agua freática (Courty, Golberg y Macphail, 1989). La circulación del agua freática pudo contribuir al deterioro químico de los huesos, a través de la degradación de la matriz proteica (Collins et al., 2002), lo cual ayudaría a explicar por qué en dos de las tres muestras enviadas a datar el colágeno resultó insuficiente. Al mismo tiempo, los cambios periódicos en las condiciones de humedad del depósito pudieron provocar una variación en la compactación del sedimento, la cual pudo ser otro de los factores que contribuyó a la fragmentación del conjunto faunístico (Johnson, 1985).

Las características del ambiente sedimentario y las propiedades tafonómicas del conjunto faunístico del sitio LB3 permiten proponer una baja integridad y resolución (sensu Binford, 1981), como consecuencia de la participación de distintos agentes y procesos en su acumulación, entre los que se destacan la actividad humana, la acción de carnívoros, la muerte natural de animales in situ y la acción hídrica. La acción combinada de estos procesos así como de la meteorización, el pisoteo, la bioturbación y los cambios en el contenido de humedad y compactación del depósito sedimentario provocaron la fragmentación de una parte importante del conjunto faunístico. Asimismo, la acción de distintos procesos que pueden provocar el desplazamiento vertical de los materiales sugiere que hay que considerar la posibilidad de mezcla de materiales depositados en distintos eventos de ocupación humana. 


\section{Aprovechamiento de recursos faunísticos}

Los cazadores-recolectores que ocuparon el sitio procesaron y consumieron distintos recursos faunísticos. La presencia de huellas de corte y fracturas de origen antrópico permiten proponer la explotación de guanaco, venado de las pampas, ñandú, armadillos y aves pequeñas. Asimismo, la presencia de alteración térmica en huesos de vizcacha, como se discutirá más adelante, sugiere que este roedor también pudo ser consumido.

La alta frecuencia de restos de guanaco indica que este ungulado fue la principal presa seleccionada por los ocupantes del sitio. La identificación de dos individuos cría sugiere que los cazadores predaron sobre grupos familiares, aunque no es posible descartar la ocurrencia de otros eventos de caza sobre otras estructuras sociales. El perfil anatómico de esta especie, caracterizado por una gran diversidad de partes correspondientes a las distintas porciones de una carcasa, permite plantear el ingreso al sitio de las carcasas completas o luego de un mínimo procesamiento en el sitio de matanza (e.g., evisceración, cuereo, desarticulación). Las fracturas de origen antrópico sobre huesos largos de guanaco sugieren el consumo de médula ósea. Por último, la alteración térmica en algunos huesos podría estar vinculada a la cocción por asado y/o al descarte de restos de alimentación en fogones.

En cuanto a las demás especies explotadas, el escaso número de especímenes recuperados indica que constituyeron recursos complementarios en la subsistencia. En el caso del venado de las pampas y el ñandú, la presencia de fracturas antrópicas sobre huesos largos muestra, al igual que en el caso del guanaco, el consumo de la médula ósea. En relación con los vertebrados pequeños, se observa una mayor explotación de los armadillos y, posiblemente, de la vizcacha. Con respecto a los primeros, el registro de huellas de corte sobre un elemento del endoesqueleto y sobre una placa dérmica indica el procesamiento de peludo. Asimismo, la presencia de placas dérmicas termoalteradas de esta especie, así como también de piche, podría estar vinculada a la cocción de estos animales en su caparazón (Frontini y Vecchi, 2014). En el caso de la vizcacha, la presencia de tres astrágalos, correspondientes a tres individuos, con alteración térmica coincide con el patrón observado en estudios experimentales de cocción por asado de carcasas completas de pequeños vertebrados. Estos estudios muestran que la alteración térmica se concentra principalmente en las porciones menos protegidas por la carne, tales como las extremidades distales de los huesos largos (Lloveras, Moreno García y Nadal, 2009; Medina, Teta y Rivero, 2012).

Las evidencias de explotación faunística coinciden con lo observado en los demás sitios de la localidad Las Brusquillas y en gran parte de los sitios del sudeste pampeano correspondientes al Holoceno tardío inicial. El registro faunístico de estos sitios muestra una estrategia de subsistencia focalizada en el guanaco, complementada con el aprovechamiento de recursos animales de menor tamaño, principalmente venado de las pampas, ñandú, armadillos y vizcacha (Álvarez, 2014; Bonomo, 2005; Frontini, 2013; Massigoge 2011, 2012; Messineo, 2011). Una situación ligeramente diferente se registra en algunos sitios de Tandilia Oriental, donde el venado de las pampas habría tenido la misma importancia que el guanaco (Quintana y Mazzanti, 2001). Este patrón económico de especialización en la caza de ungulados se habría establecido en la región Pampeana en la segunda mitad del Holoceno medio y habría continuado sin grandes cambios hasta comienzos del Holoceno tardío final, cuando empieza a manifestarse en algunas áreas la ocurrencia de procesos de diversificación e intensificación en la subsistencia (Álvarez, 2014; Frontini, 2013; González, 2005; Martínez y Gutiérrez, 2004; Quintana y Mazzanti, 2014; Stoessel y Martínez, 2014).

\section{Tecnología lítica}

El conjunto lítico del sitio LB3 está conformado por numerosos desechos de talla, escasos artefactos formatizados y un núcleo. Para la confección de los artefactos se 
seleccionó preferentemente OGSB, la cual era la materia prima lítica de mejor calidad disponible en el sudeste pampeano (Bayón, Flegenheimer, Valente y Pupio, 1999). Esta roca pudo ser obtenida en el sector centro-sur del sistema serrano de Tandilia, a una distancia de unos $80 \mathrm{~km}$ del sitio, donde se han identificado canteras y talleres arqueológicos (Colombo, 2011). Del mismo modo, el abastecimiento de ftanita, la segunda roca en importancia, pudo llevarse a cabo en este sector, ya que se encuentra disponible en el mismo complejo de canteras (Flegenheimer y Bayón, 2002). Otra fuente potencial de abastecimiento de ftanita es el complejo de canteras y talleres de las Sierras Bayas, en el extremo occidental de Tandilia, a unos $150 \mathrm{~km}$ de distancia del sitio (Messineo y Barros, 2015). No obstante, considerando las diferencias en el costo de transporte entre estos dos sectores, así como el uso secundario de esta roca en LB3, resulta más plausible su obtención en el primer sector mencionado, conjuntamente con el abastecimiento de OGSB. De este mismo sistema serrano podrían provenir el cuarzo, el granito y el esquisto, ya que estas rocas se encuentran presentes en el basamento igneo-metamórfico (Bayón et al., 1999). Por último, la toba silicificada pudo haber sido obtenida en los afloramientos rocosos del interior del área Interserrana, a una distancia mínima del sitio de 26 km (Flegenheimer y Bayón, 2002).

La OGSB pudo haber arribado al sitio bajo la forma de núcleos, lascas y/o instrumentos en distintos estados de manufactura. El núcleo recuperado sugiere una preparación previa antes de su ingreso al sitio. La talla de esta roca estuvo orientada a la producción de lascas, algunas de las cuales fueron usadas como soportes para la elaboración de instrumentos. Estos fueron confeccionados mayormente por percusión directa, mediante técnica unifacial. No obstante, algunos desechos indican el empleo de talla bipolar, técnica que podría estar indicando el uso intensivo de esta roca, como ha sido planteado para otros sitios de la región distantes de los afloramientos (Barros, Martínez y Gutiérrez, 2014; Bayón et al., 2006; Massigoge y Pal, 2011). La gran variedad tipológica sugiere que los instrumentos confeccionados sobre OGSB fueron utilizados en diversas actividades, entre las que podría incluirse el procesamiento de los recursos faunísticos. El alto porcentaje de desechos de talla muy pequeños así como la presencia de algunas lascas de reactivación, indican que en el sitio también se llevaron a cabo actividades vinculadas a la formatización final de instrumentos y a la manutención y reactivación de sus filos.

En lo que respecta a la ftanita, los artefactos son escasos. Así como se observa en otros sitios cercanos, esta roca se habría empleado preferentemente para la confección de raspadores, lo cual, como señalaron otros investigadores, podría estar indicando una mejor adecuación de esta materia prima para este fin (Barros et al., 2014; Bayón et al., 2006). La ftanita pudo haber sido transportada al sitio bajo la forma de núcleos pequeños, formas-base o instrumentos. La presencia exclusiva de desechos muy pequeños y pequeños sugiere que estas últimas formas de ingreso pudieron ser las más comunes. Los productos de talla sobre esta materia prima indican que en el sitio se realizaron actividades de formatización final y reactivación de filos. En relación con las restantes materias primas se propone su arribo al sitio mayormente como instrumentos ya finalizados.

El conjunto lítico del sitio LB3 presenta semejanzas con los otros sitios del área de estudio y del interior de la llanura Interserrana en general, donde predomina el uso de OGSB desde los momentos iniciales de ocupación y a lo largo del Holoceno (Barros et al., 2014; Bayón et al., 2006). Las características de los conjuntos líticos del área de estudio correspondientes al Holoceno tardío evidencian que las rocas habrían ingresado en un avanzado estado de reducción, principalmente como núcleos preparados, lascas o instrumentos. Estos datos permiten proponer que la modalidad de traslado de rocas representada en el área de estudio es el aprovisionamiento de los individuos (sensu Kuhn, 1995). Por el momento, no se han identificado evidencias de aprovisionamiento 
de los lugares (sensu Kuhn, 1995), modalidad que se encuentra representada en otros contextos del Holoceno tardío de la llanura Interserrana (Bayón et al., 2006; Bonomo, 2005; Martínez y Mackie, 2003-2004). El empleo de esta última estrategia, la cual implica el traslado de núcleos o lascas grandes y su almacenamiento en sitios donde se ha planificado regresar, ha sido vinculado a los cambios en la demografía, movilidad y territorialidad que atravesaron las sociedades cazadoras-recolectoras hacia fines del Holoceno (Bayón et al., 2006; Martínez y Mackie, 2003-2004). La no representación de esta forma de traslado de rocas en el área de estudio podría ser consecuencia de un uso diferente de este espacio con respecto a sectores vecinos (ver discusión en Massigoge y Pal, 2011). No obstante, una hipótesis que deberá ser evaluada en futuros trabajos a escala regional es que esta estrategia se haya vuelto más frecuente hacia fines del Holoceno tardío, momento a partir del cual se observan cambios de gran importancia en otras esferas, como la subsistencia.

\section{Conclusiones}

El registro arqueológico del sitio Las Brusquillas 3 presenta una baja integridad y resolución. No obstante, su estudio amplía la información de base arqueológica disponible para el Holoceno tardío de la región pampeana, la cual es aún limitada, y permite plantear y discutir algunas tendencias en la subsistencia y la tecnología lítica para este lapso cronológico. Las evidencias obtenidas en LB3 concuerdan con las propuestas de otros investigadores para el sudeste pampeano de una subsistencia focalizada en la explotación de ungulados, principalmente guanaco, y una tecnología lítica mayormente unifacial sobre materias primas de las sierras de Tandilia, destacándose el uso preferencial de OGSB en los sitios de la llanura Interserrana. Si bien en algunos sectores de la llanura se han identificado evidencias de aprovisionamiento de los lugares con materias primas, la implementación de esta estrategia no ha sido identificada en LB3 así como en otros sitios del área de estudio correspondientes al mismo lapso temporal, lo cual podría estar indicando un uso diferencial del espacio o un sesgo cronológico del registro analizado. Por último, el estudio del sitio LB3 aporta al conocimiento de las re-ocupaciones humanas de un mismo entorno en distintos momentos del Holoceno.

\section{Agradecimientos}

Estas investigaciones se llevaron a cabo en el marco de la Unidad Ejecutora INCUAPACONICET (Facultad de Ciencias Sociales, UNICEN). Los trabajos de campo y laboratorio fueron financiados por la ANPCyT (PICT No 2008-0814 y No 2010-0235). Se desea agradecer especialmente a la Municipalidad de San Cayetano y a los vecinos de dicha localidad por el apoyo brindado durante los trabajos de campo, en especial a los Sres. Oscar Oldano y Ricardo Belloni. También se agradece a C. Kaufmann por su colaboración en la determinación de las clases de edad de guanaco y a M. C. Álvarez, P. Messineo y los evaluadores por la lectura crítica de este trabajo así como sus sugerencias. No obstante, las ideas vertidas son de exclusiva responsabilidad de los autores. 


\section{Q Referencias citadas}

"Álvarez, M. C. (2014). Subsistence patterns during the Holocene in the Interserrana area (Pampean region, Argentina): Evaluating intensification in resource exploitation.Journal of Anthropological Archaeology, 34, 54-65.

"Andrews, P. (1990). Owls, Caves and Fossils. Londres: Natural History Museum Publications.

» Aschero, C. A. (1975). Ensayo para una clasificación morfológica de artefactos líticos aplicada a estudios tipológicos comparativos. Informe al CONICET. Manuscrito inédito.

» Aschero, C. A. (1983). Ensayo para una clasificación morfológica de artefactos líticos aplica a estudios tipológicos comparativos. Apéndices A-C. Revisión. Cátedra de Ergología y Tecnología, Facultad de Filosofía y Letras, Universidad de Buenos Aires. Manuscrito inédito.

» Barros, M. P., Martínez, G. y Gutiérrez, M. A. (2014). Análisis de los materiales líticos del sitio Paso Otero 4 (partido de Necochea, provincia de Buenos Aires). Avances en el conocimiento de las estrategias tecnológicas en el curso medio del río Quequén Grande durante el Pleistoceno tardío-Holoceno. Relaciones de la Sociedad Argentina de Antropología, XXXIX(1), 119-144.

» Bayón, C., Flegenheimer, N. y Pupio, A. (2006). Planes sociales en el abastecimiento y traslado de roca en la pampa bonaerense en el Holoceno temprano y tardío. Relaciones de la Sociedad Argentina de Antropología, XXXI, 19-45.

» Bayón, C., Flegenheimer, N., Valente, M. y Pupio, A. (1999). Dime cómo eres y te diré de dónde vienes: procedencia de rocas cuarcíticas en la Región Pampeana. Relaciones de la Sociedad Argentina de Antropología, XXIV, 187-217.

" Behrensmeyer, A. K. (1978). Taphonomic and ecological information from bone weathering. Paleobiology, 4(2), 150-162.

» Bellelli, C., Guraieb, A. y García, J. (1985-1987). Propuesta para el análisis y procesamiento por computadora de desechos de talla lítica (DELCO-Desechos Líticos Computalizados). Arqueología Contemporánea, 2(1), 36-53.

"Berón, M. (2007). Circulación de bienes como indicador de interacción entre las poblaciones de la Pampa Occidental y sus vecinos. En C. Bayón, A. Pupio, M. I. González, N. Flegenheimer y M. Frère (Eds.), Arqueología en las Pampas (Tomo I) (pp. 345-364). Buenos Aires: Sociedad Argentina de Antropología.

" Binford, L. R. (1981). Bones: Ancient Men and Modern Myths. Nueva York: Academic Press.

»Binford, L. R. (1984). Faunal Remains from Klasies River Mouth. Orlando: Academic Press.

» Bonomo, M. (2005). Costeando las Llanuras: Arqueología del Litoral Marítimo Pampeano. Buenos Aires: Sociedad Argentina de Antropología.

"Collins, M. J., Nielsen-Marsh, C. M., Hiller, J., Smith, C. I., Roberts, J. P., Prigodich, R. V., Wess, T. J., Csapò, T. J., Millard, A. R. y Turner-Walker, G. (2002). The survival of organic matter in bones: a review. Archaeometry, 44(3), 383-394.

"Colombo, M. (2011). El área de abastecimiento de las ortocuarcitas del grupo Sierras Bayas y las posibles técnicas para su obtención entre los cazadores y recolectores pampeanos. Intersecciones en Antropología, 12, 231-243. 
» Courty, M. A., Golberg, P. y Macphail, R. (1989). Soils and Micromorphology in Archaeology. Cambridge: Cambridge University Press.

» Eren, M. I., Durant, A., Neudorf, C., Haslam, M., Shipton, C., Bora, J., Korisettar, R., Petraglia, M. (2010). Experimental examination of animal trampling effects on artifact movement in dry and water saturated substrates: a test case from South India. Journal of Archaeological Science, 37, 3010-3021.

» Fidalgo, F., De Francesco, F. O. y Colado, U. (1973). Geología superficial de las hojas Castelli, J. M. Cobo y Monasterio (Provincia de Buenos Aires). En Actas del $5^{\circ}$ Congreso Geológico Argentino (Tomo 4) (pp. 27-39). Buenos Aires: Asociación Geológica Argentina.

» Fisher, J. W. Jr. (1995). Bone surface modifications in zooarchaeology. Journal of Archaeological Method and Theory, 2(1), 7-68.

» Flegenheimer, N. y Bayón, C. (2002). Cómo, cuándo y dónde? Estrategias de abastecimiento lítico en la Pampa Bonaerense. En D. Mazzanti, M. Berón \& F. Oliva (Eds.), Del Mar a los Salitrales, Diez Mil Años de Historia Pampeana en el Umbral del Tercer Milenio (pp. 231-241). Mar del Plata: Facultad de Humanidades, Universidad Nacional de Mar del Plata.

» Frontini, R. (2013). Aprovechamiento faunístico en entornos acuáticos del sudoeste bonaerense durante el Holoceno (6.900-70o años AP). Relaciones de la Sociedad Argentina de Antropología, XXXVIII(2), 493-519.

» Frontini, R. y Escosteguy, P. (2012). Chaetophractus villosus: a disturbing agent for archaeological contexts. International Journal of Osteoarchaeology, 22(5), 603-615.

» Frontini, R. y Vecchi, R. (2014). Thermal alteration of small mammal from El Guanaco 2 site (Argentina): an experimental approach on armadillos bone remains (Cingulata, Dasypodidae). Journal of Archaeological Science, 44, 22-29.

»González, M. I. (2005). Arqueología de Alfareros, Cazadores y Pescadores Pampeanos. Buenos Aires: Sociedad Argentina de Antropología.

» Gutiérrez, M. A. y Kaufmann, C. A. (2007). Criteria for the identification of formation processes in guanaco (Lama guanicoe) bone assemblages in fluvial-lacustrine environments. Journal of Taphonomy, 5(4), 151-176.

» Hogg, A. G., Hua, Q.. Blackwell, P. G., Buck, C. E., Guilderson, T. P., Heaton, T. J., Niu, M., Palmer, J. G., Reimer, P. J., Reimer, R. W., Turney, C. S. M. y Zimmerman, S. R. H. (2013). SHCal 13 Southern Hemisphere Calibration, 0-50,000 Years cal BP. Radiocarbon, 55(4), 1889-1903.

» Johnson, E. (1985). Current developments in bone technology. En M. B. Schiffer (Ed.), Advances in Archaeological Method and Theory (Volume 8) (pp. 157-235). Orlando: Academic Press.

»Kaufmann, C. A. (2009). Estructura de Edad y Sexo en Guanaco. Estudios Actualísticos y Arqueológicos en Pampa y Patagonia. Buenos Aires: Sociedad Argentina de Antropología.

» Kaufmann, C. A., Gutiérrez, M. A., Álvarez, M. C., González, M. E. y Massigoge, A. (2011). Fluvial dispersal potential of guanaco bones (Lama guanicoe) under controlled experimental conditions. Journal of Archaeological Science, 38(2), 334-344.

» Kuhn, S. L. (1995). Mousterian Lithic Technology. An Ecological Perspective. Princeton: Princeton University Press.

» Lloveras, L., Moreno-García, M. y Nadal, J. (2009). Butchery, cooking and human consumption marks on rabbit (Oryctolagus cuniculus) bones: An experimental study. Journal of Taphonomy, 7(2-3), 179-201.

» Lyman, R. L. (1994). Vertebrate Taphonomy. Cambridge: Cambridge University Press. 
» Martínez, G. y Gutierrez, M. A. (2004). Tendencias en la explotación humana de la fauna durante el Pleistoceno final y Holoceno en la Región Pampeana (Argentina). En G. Mengoni Goñalons (Ed.), Zooarchaeology of South America (pp. 81-98). Oxford: BAR International Series 1298, Archaeopress.

» Martínez, G. A., Landini, C. y Bonomo, M. (1997-1998). Análisis de los artefactos líticos del sitio Paso Otero 3: Organización de la tecnología lítica en el curso medio del río Quequén Grande. Publicaciones en Arqueología, 49, 3-22.

» Martínez, G. A. y Mackie, Q. (2003-2004). Late Holocene human occupation of the Quequén Grande River valley botton: settlement systems and an example of a built environment in the Argentine Pampas. Before Farming, 4, 178-202.

"Massigoge, A. (2007). Resultados preliminares de las investigaciones arqueológicas desarrolladas en el partido de San Cayetano (provincia de Buenos Aires). En C. Bayón, A. Pupio, M. I. González, N. Flegenheimer y M. Frère (Eds.), Arqueología en las Pampas (Tomo 2) (pp. 511-534). Buenos Aires: Sociedad Argentina de Antropología.

" Massigoge, A. (2011). Nuevas evidencias arqueológicas del Holoceno tardío en el área Interserrana: el sitio Las Brusquillas 2 (Partido de San Cayetano, Provincia de Buenos Aires, Argentina). Cazadores-Recolectores del Cono Sur. Revista de Arqueología, 5, 179-195.

"Massigoge, A. (2012). Las Brusquillas 1 (partido de San Cayetano, provincia de Buenos Aires): un nuevo sitio del Holoceno tardío del área Interserrana de la región Pampeana. Intersecciones en Antropología, 13, 377-392.

" Massigoge, A. y Pal, N. (2011). Producción y uso de artefactos líticos en contextos cazadores-recolectores del Holoceno tardío del área Interserrana (Argentina): análisis integral de la diversidad tecno-morfológica y funcional. Revista Española de Antropología Americana, 41(1), 51-73.

»Mazzanti, D. (2006). La constitución de territorios sociales durante el Holoceno tardío. El caso de las Sierras de Tandilia, Argentina. Relaciones de la Sociedad Argentina de Antropología, XXXI, 277-300.

» Medina, M. E., Teta, P. y Rivero, D. (2012). Burning damage and small-mammal human consumption in Quebrada del Real 1 (Cordoba, Argentina): an experimental approach. Journal of Archaeological Science, 39, 737-743.

» Messineo, P. G. (2011). Investigaciones arqueológicas en la cuenca superior del Arroyo Tapalqué. Un modelo de ocupación humana para el centro de la subregión Pampa Húmeda durante el Holoceno tardío. Intersecciones en Antropología, 12, 275-291.

" Messineo, P. G. y Barros, M. P. (2015). Lithic raw materials and modes of exploitation in quarries and workshops from the center of the Pampa grasslands of Argentina. Lithic Technology, 40(1), 3-20.

" Olsen, S. L. y Shipman, P. (1988). Surface modification on bone: trampling versus butchery. Journal of Archaeological Science, 15(5), 535-553.

» Payne, S. (1975). Partial recovery and sample bias. En A. T. Clason (Ed.), Archaezoological Studies (pp. 7-17). Amsterdam: North Holland.

»Politis, G. G. (2008). The Pampas and Campos of South America. En H. Silverman y W. H. Isbell (Eds.), Handbook of South American Archaeology (pp. 235-260). Nueva York: Springer.

» Politis, G. G. (2012). Las poblaciones prehispánicas. En H. Otero (Ed.), Historia de la Provincia de Buenos Aires. Población, Ambiente y Territorio (pp. 213-247). Buenos Aires: Universidad Pedagógica Nacional (UNIPE) y Editora y Distribuidora Hispano Americana S. A. (EDHASA). 
»Quintana, C. A. y Mazzanti, D. L. (2001). Selección y aprovechamiento de recursos faunísticos. En D. L. Mazzanti y C. A. Quintana (Eds.), Cueva Tixi: Cazadores y Recolectores de las Sierras de Tandilia Oriental. Geología, Paleontología y Zooarqueología (Publicación Especial I) (pp. 181-209). Mar del Plata: Laboratorio de Arqueología, Universidad Nacional de Mar del Plata.

»Quintana, C. A. y Mazzanti, D. L. (2010). Caza menor en sitios arqueológicos de Tandilia Oriental. En M. Gutiérrez, M. de Nigris, P. M. Fernández, M. Giardina, A. Gil, A. Izeta, G. Neme y H. Yacobaccio (Eds.), Zooarqueología a Principios del Siglo XX: Aportes Teóricos, Metodológicos y Casos de Estudio (pp. 307-319). Ayacucho: Libros del Espinillo.

»Quintana, C. A. y Mazzanti, D. L. (2014). La emergencia de la diversificación de la caza en las sierras de Tandilia Oriental durante el Holoceno tardío final. Comechingonia. Revista de Arqueología, 18, 41-64.

»Stoessel, L. y Martínez, G. (2014). El proceso de intensificación en la transición pampeano-patagónica oriental. Discusión y perspectivas comparativas con regiones aledañas. Comechingonia. Revista de Arqueología, 18, 65-64.

»Stuiver, M. y Reimer, P. J. (1993). Extended 14C data base and revised CALIB 3.0 14C age calibration program. Radiocarbon, 35, 215-230.

»White, T. E. (1953). A method of calculating the dietary percentage of various food animals utilized by aboriginal peoples. American Antiquity, 19, 396-398.

»Wood, W. R. y Johnson, D. L. (1978). A survey of disturbance processes in archaeological site formation. En M. B. Schiffer (Ed.), Advances in Archaeological Method and Theory (Volume 1) (pp. 315-381). Orlando: Academic Press. 